\title{
The assessment and management of chemotherapy-related toxicities in patients with breast cancer, colorectal cancer, and Hodgkin and non-Hodgkin lymphomas: a scoping review
}

\author{
Fox, P.A., Darley, A., Furlong, E., Miaskowski, C., Patiraki, E., Armes, Jo., Ream, E.,
} Papadopoulou, C., McCann, L., Kearney, N. and Maguire, R. (2017)

\begin{abstract}
PURPOSE

The purpose of the eSMART (Electronic Symptom Management using the Advanced Symptom Management System (ASyMS) Remote Technology) study is to evaluate the use of mobile phone technology to manage chemotherapy-related toxicities (CRTs) in people with breast cancer (BC), colorectal cancer (CRC), Hodgkin's lymphoma (HL), and non-Hodgkin lymphoma (NHL)) across multiple European sites. One key objective was to review the published and grey literature on assessment and management of CRTs among patients receiving primary chemotherapy for BC, CRC, $\mathrm{HL}$, and NHL to ensure that ASyMS remained evidence-based and reflected current and local practice.
\end{abstract}

METHODS:

Three electronic databases were searched for English papers, with abstracts available from 01/01/2004-05/04/2014. For the grey literature, relevant clinical practice guidelines (CPGs)/evidence-based resources (EBRs) from the main international cancer organisations were reviewed as were symptom management (SM) protocols from the sites.

RESULTS:

After full-text screening, 27 publications were included. The majority $(n=14)$ addressed fatigue and focused on BC patients. Relevant CPGs/EBRs were found for fatigue $(n=4)$, nausea/vomiting $(n=5)$, mucositis $(n=4)$, peripheral neuropathy $(n=3)$, diarrhoea $(n=2)$, constipation $(n=2)$, febrile neutropenia/infection ( $n=7)$, palmar plantar erythrodysesthesia (PPE) $(n=1)$, and pain $(n=4)$. SM protocols were provided by $>40 \%$ of the clinical sites.

\section{CONCLUSIONS:}

A need exists for empirical research on SM for PPE, diarrhoea, and constipation. Research is needed on the efficacy of self-care strategies in patients with BC, CRC, HL, and NHL. In general, consistency exists across CPGs/EBRs and local guidelines on the assessment and management of common CRTs.

Keywords: assessment; management; chemotherapy; toxicity; symptom; scoping review; clinical practice guideline, self-care 


\section{The assessment and management of chemotherapy-related toxicities in patients with breast cancer, colorectal cancer, and Hodgkin and non-Hodgkin lymphomas: a scoping review}

\section{Introduction}

In 2013, the European Union (EU) funded eSMART'; a study evaluating Electronic Symptom Management using the Advanced Symptom Management System (ASyMS ${ }^{2}$ ) mobile phone technology for the management of chemotherapy-related toxicities (CRTs) in people with breast cancer (BC), colorectal cancer (CRC), Hodgkin's lymphoma (HL), and non-Hodgkin lymphoma (NHL)) cancers across multiple clinical sites in Europe. Developed in conjunction with cancer clinicians and people with cancer (Kearney et al., 2006, Gibson et al., 2009, Kearney et al., 2009, Gibson et al., 2010, Maguire et al., 2015), ASyMS is a mobile phone based remote monitoring system that enables real time monitoring of CRTs through patients' completion of electronic patient reported outcome measures (ePROMs). ASyMS facilitates immediate tailored management of CRTs in the home care setting, automatic and immediate triaging of care when toxicities exceed clinical norms, and the provision of evidence-based self-care advice.

At the outset, a key objective of eSMART was to undertake a review of the published and grey literature (international, national and local clinical guidelines) related to the assessment and management of CRTs among patients receiving primary chemotherapy for $\mathrm{BC}, \mathrm{CRC}, \mathrm{NHL}$, and $\mathrm{HL}$ to ensure that ASyMS (risk algorithms, symptom protocols, self-care advice) was evidence-based, updated $^{3}$, and reflected current and local practice. Consistent with the toxicities assessed and managed using ASyMS, this review was limited to the most common CRTs (i.e., nausea, vomiting, diarrhoea, constipation, mucositis/stomatitis, chemotherapy induced peripheral neuropathy (CIPN), hand-foot syndrome (palmar plantar erythrodysesthesia (PPE)), fever (or febrile neutropenia (FN)), infection, fatigue, pain). The purpose of this paper is to report on the background, objectives, methods, and key findings from the published and grey literature review.

\section{Methods}

Search Strategy (published literature)

With the assistance of a college librarian, a search strategy with five search strings (Figure 1, Appendix 1) was designed. This search was conducted within three electronic databases (i.e., PubMed, CINAHL, PsycARTICLES) using specific Boolean operators, truncation markers, and MeSH headings. All searches were limited to English papers, involving human participants over 18 years of age, with an abstract available dating from January 1st 2004 to April 5th 2014. Given the recent literature review ${ }^{3}$, it was deemed sufficient to target empirical literature published within the previous ten years. The results were exported into WebEndNote $\bigodot$ and articles were screened in two

\footnotetext{
${ }^{1}$ Electronic Symptom Management using the Advanced Symptom Management System

${ }^{2}$ Advanced Symptom Management System

${ }^{3}$ The content of the existing system was rigorously developed following systematic reviews of the literature and expert clinician consensus in the UK and Australia in 2011.
} 
stages. First, titles and abstracts of all retrieved articles were screened for eligibility by two reviewers $(C P 1, A D)$. Where relevance was unclear from the title or abstract, a copy of the full text was obtained.

One hundred and eighty articles met the inclusion criteria (see Table 1 ) and full text versions were obtained. The second phase of screening involved assessment of the full texts $(\mathrm{N}=180)$ by five reviewers ( $C P 1, A D, E F, P F, A M)$. Studies were selected if they met the inclusion criteria. To further ensure the quality of the included literature, articles were required to meet the criteria outlined by the UK's Department of Health (DoH) 'Typology of Supportive Evidence' (UK DoH, 2011) (Table 1). Once all of the articles were screened, the eligibility outcomes were cross-checked and examined by a sixth reviewer (CP2). This reviewer was given $10 \%$ of the full text articles to compare her rating of outcomes with those of the original screening team. Seven discrepancies were identified and three reviewers (CP1, CP2, AD) made the final decision regarding relevance. A PRISMA diagram of the systematic review process that depicts the reasons for inclusion and exclusion criteria of articles is presented in Figure 2. 
Table 1 Eligibility guidelines for screening citations

In the context of patients diagnosed with either $\mathrm{BC}, \mathrm{CRC}, \mathrm{NHL}$, or $\mathrm{HL}$, studies which

\begin{tabular}{|c|c|}
\hline Inclusion & $\begin{array}{l}\text { 1. included adult patients (18+ years) } \\
\text { 2. focused exclusively on symptom management and self-care strategies for nausea, } \\
\text { vomiting, diarrhoea, constipation, fever (or FN), infection, CIPN, mucositis (or } \\
\text { stomatitis), fatigue, PPE, pain } \\
\text { 3. investigated self-care strategies (as a primary outcome) } \\
\text { 4. involved aspects of symptom management and/or assessment conducted by } \\
\text { clinicians } \\
\text { 5. reviewed the use of complementary and alternative medicine (CAM) therapies that } \\
\text { were relevant to self-care of the symptoms of interest }\end{array}$ \\
\hline $\begin{array}{l}\text { Exclusion } \\
\text { Criteria }\end{array}$ & $\begin{array}{l}\text { 1. focused on the experience (or prevalence) of symptoms with no reference to } \\
\text { management or self-care } \\
\text { 2. reported results of CAM therapies } \\
\text { 3. focused on patients with Burkitt's lymphoma; patients < } 18 \text { years; patients in } \\
\text { survivorship following chemotherapy completion; patients with metastatic disease } \\
\text { and in the context of palliative care; patients undergoing bone marrow } \\
\text { transplantation (BMT) } \\
\text { 4. reported validation of tools } \\
\text { 5. focused on symptoms not listed in the inclusion criteria } \\
\text { 6. investigated the use of medicinal products to treat or manage CRTs }\end{array}$ \\
\hline
\end{tabular}

\begin{tabular}{|c|c|c|}
\hline $\begin{array}{l}\text { Included } \\
\text { Papers }\end{array}$ & A1 & $\begin{array}{l}\text { Systematic reviews which included at least one randomised controlled trial (RCT) } \\
\text { (e.g. Systematic Reviews from Cochrane or Centre for Reviews and Dissemination). }\end{array}$ \\
\hline & A2 & Other systematic and high quality reviews which synthesise references. \\
\hline & B1 & Individual RCTs. \\
\hline & B2 & Individual non-randomised, experimental/intervention studies. \\
\hline & B3 & $\begin{array}{l}\text { Individual well-designed non-experimental studies, controlled statistically if } \\
\text { appropriate; includes studies using case control, longitudinal, cohort, matched } \\
\text { pairs, or cross-sectional random sample methodologies, and well-designed } \\
\text { qualitative studies; well-designed analytical studies including secondary analysis. }\end{array}$ \\
\hline Excluded & C1 & Descriptive and other research or evaluation not in B (e.g. convenience samples). \\
\hline & $\mathrm{C} 2$ & Case studies and examples of good practice. \\
\hline & D & $\begin{array}{l}\text { Summary review articles and discussions of relevant literature and conference } \\
\text { proceedings not otherwise classified. }\end{array}$ \\
\hline
\end{tabular}


Once the final set of relevant papers were identified $(\mathrm{N}=27)$, key data were extracted and tabulated (see Appendix 2).
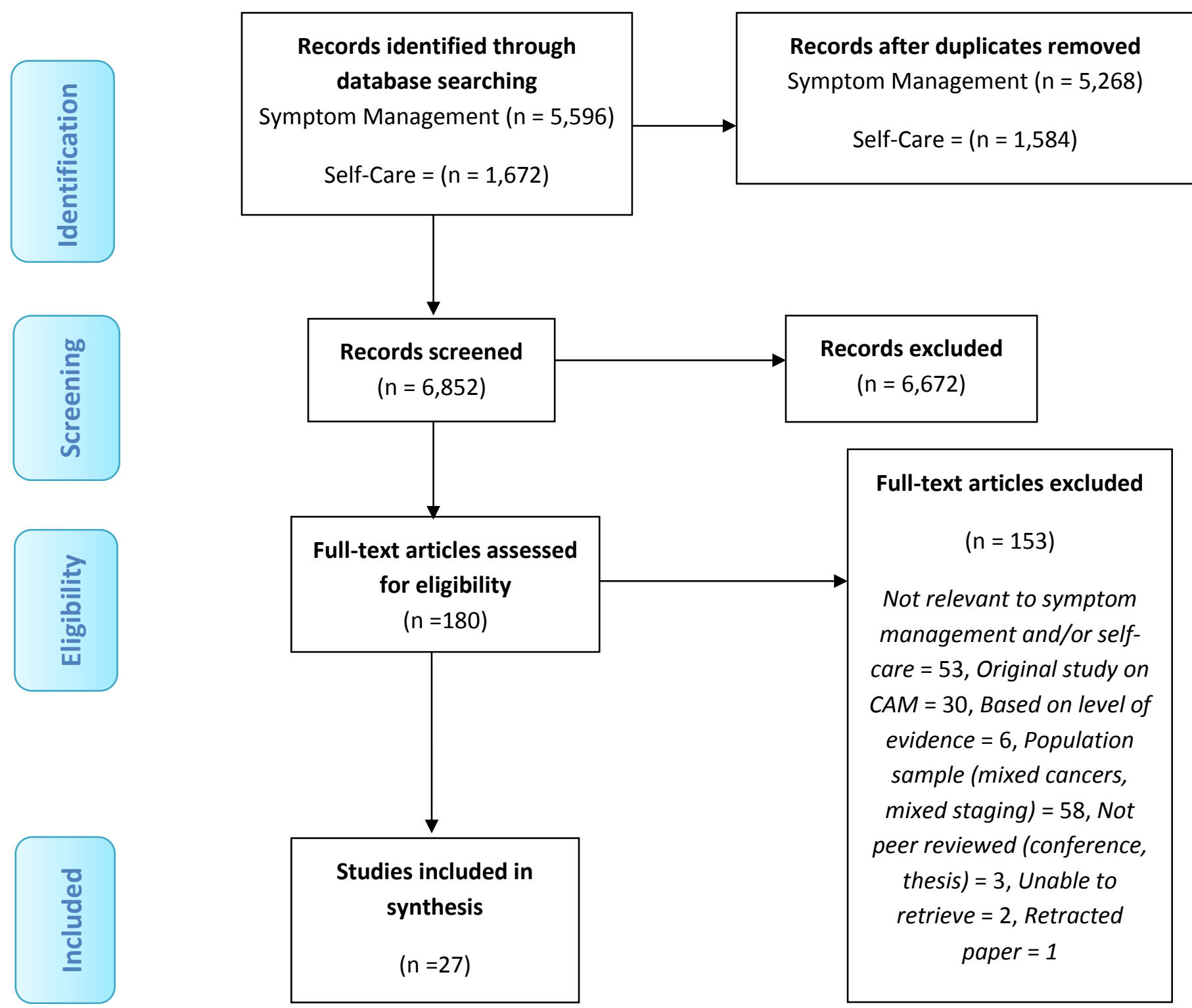

Figure 2. Screening process

\section{Methods adopted to review the grey literature}

This scoping review included a focused appraisal of the relevant grey literature to minimise the omission of important information which is not published (Blackhall and Ker, 2007). This approach included a review of symptom management protocols across the participating clinical sites $(N=13)$ in the study to achieve consistency with reference to the symptom management and self-care advice utilised for ASyMS. More specifically, relevant clinical practice guidelines (CPGs)/evidence-based resources (EBRs) from the main international medical and nursing cancer organisations were reviewed (i.e., the European Society for Medical Oncology (ESMO), the American Society for Clinical 
Oncology (ASCO), the National Comprehensive Cancer Network (NCCN), the Multinational Association for Supportive Care in Cancer (MASCC), the Oncology Nursing Society (ONS), the European Oncology Nursing Society (EONS)). While acknowledging that some were published, CPGs/EBRs were included under the grey literature heading to decrease the likelihood of omitting guidelines that were not published in journals (e.g., EONS guidelines and ONS Putting Evidence into Practice (PEP) online resources). The United Kingdom Oncology Nursing Society (UKONS) was the only national organisation with symptom management guidelines available in English. In addition, each clinical site involved in the study was asked to provide copies of their symptom management protocols and/or guidelines if they were available in English.

\section{Results}

The findings from this review are structured around each of the symptoms, that is, each symptom is discussed with reference to the relevant published and grey literature. For the published literature, the initial search strategy elicited 7,268 unique publications. After a full-text screening process, 27 publications were included in this review. The majority of the papers were either reviews $(n=7$, including four systematic reviews (SR)) or RCTs $(n=7)$. With the exception of a single arm pilot study, the remaining studies were descriptive utilising a quantitative $(n=9)$, qualitative $(n=2)$, or mixed methods ( $n=1)$ approach (Appendix 2). The majority of the papers $(n=14)$ addressed fatigue (either as a primary or secondary endpoint in intervention studies or in addition to other symptoms in the reviews and descriptive studies) and these papers primarily focused on patients with BC. Nine papers addressed multiple symptoms while CIPN was the focus of three papers. Chemotherapyinduced nausea and vomiting (CINV) were addressed separately in two papers and together in one paper. Oral mucositis (OM) and pain were both the focus of two separate papers. None of the papers focused on symptom management for diarrhoea, constipation, or PPE. The majority of the studies addressed various interventions for symptom management. Only three papers (Chou et al., $2007^{4}$, Speck et al., 2012, Spichiger et al., 2012) addressed self-care strategies.

Relevant CPGs/EBRs were found for fatigue ( $n=4)$, CINV ( $n=5)$, OM ( $n=4)$, CIPN ( $n=3)$, diarrhoea $(n=2)$, constipation ( $n=2), F N /$ neutropenic sepsis/infection $(n=7), \operatorname{PPE}(n=1)$, and pain $(n=4)$ (Appendix 3 , Tables 4-12, inclusive). Information on symptom management protocols and self-care guidance was provided by over $40 \%$ of the participating clinical sites (sites did not have the protocols/guidance available in English and/or did not have institution-specific guidelines) (Tables 3-12, inclusive).

\section{Fatigue}

The review of the published literature found 14 papers on fatigue. Ten of these studies focused on various fatigue-related symptom management interventions. However, with the exception of one study that evaluated the effect of exercise on patients with lymphoma (Courneya et al., 2009), the others focused on fatigue in BC. None of the studies addressed symptom management interventions (other than self-care) for fatigue in CRC. More specifically, this review found two multicentre RCTs (Courneya et al., 2007a, Courneya et al., 2007b, Courneya et al., 2013) and one single arm pilot study (Ligibel et al., 2010) that focused on the impact of exercise for the management of fatigue in women receiving adjuvant treatment for $B C$.

\footnotetext{
${ }^{4}$ According to Chou et al. (2007), approximately 2-3 self-care strategies were used to manage each symptom reported in their study. While the specific self-care strategies were not identified, they were reported to be of low to moderate effectiveness.
} 
Although initially, neither aerobic exercise training (AET) nor resistance exercise training (RET) significantly improved fatigue levels over usual care, positive trends were noted for both exercise groups (Courneya et al., 2007a). Moreover, a six month post-intervention follow-up of the same study (Courneya et al., 2007b) reported improved levels of fatigue $(p=.013)$ for patients who confirmed adherence to both AET and RET. Ligibel and colleagues (2010) reported a trend toward improved fatigue levels in a similar cohort of patients who completed a home-based, 12 week moderate-intensity aerobic exercise intervention with telephone counselling. More recently, Courneya et al. (2013) reported that a higher dose (50-60 minutes) of aerobic or combined exercise (aerobic and resistance) were both feasible and safe for patients receiving adjuvant chemotherapy for $B C$ and may be superior to standard doses (25-30 minutes) for managing symptoms such as fatigue.

The benefit of exercise for the management of fatigue both during and after treatment for BC was highlighted in three reviews (two SR (Kirshbaum, 2006, Wanchai et al., 2011) and one nonsystematic but comprehensive review (Loprinzi et al., 2008)). Wanchai and colleagues (2011) suggested that other interventions such as education and counselling, sleep therapy, and complementary therapy (CT) were likely to be beneficial for managing fatigue in BC. Courneya et al. (2009) evaluated the impact of 12 weeks of supervised AET versus usual care for patients with $\mathrm{HL}$ and NHL, receiving chemotherapy or no treatment. According to the authors, the AET group had superior effects for outcomes including fatigue $(p=.013)$.

Only one study (Spichiger et al., 2012) explicitly addressed self-care strategies used to decrease cancer-related fatigue. According to the authors, patients with lymphoma, BC, CRC, and lung cancer employed various intuitive self-care approaches (most often rest) to manage their fatigue although they had difficulty explaining their rationale for the approaches chosen or whether or not they were effective. In addition, Spichiger et al. (2012) found that while patients reported that they were well informed about fatigue by clinicians on commencing chemotherapy, virtually no fatigue management support was provided during chemotherapy. Chou et al. (2007) reported on self-care strategies used for chemotherapy-induced fatigue ${ }^{4}$.

Four cancer organisations developed fatigue specific CPGs/EBRs, namely, UKONS (2013), ASCO (Bower et al., 2014), ONS (Mitchell et al., 2007, ONS, 2014), and the NCCN (2014) (Table 4). The ASCO (2014) guideline was developed to address fatigue in adult cancer survivors following completion of primary therapy. Focused on patients who present as an emergency/unplanned admission, the UKONS (2013) guideline is more relevant for the initial rather than the long term management of fatigue. That said, all of the guidelines are broadly consistent with reference to fatigue assessment and management. In terms of assessment, the guidelines highlight the importance of regular screening for fatigue and the utilisation of assessment tools and comprehensive history taking to identify fatigue and treatable contributing factors. Similarly, the symptom management strategies recommended for fatigue are broadly consistent, including exercise, treatment of contributing factors, various psychoeducational interventions, cognitive behavioural therapy (CBT)/behavioural therapy (BT), CT and if necessary medications such as psychostimulants.

Guidelines for fatigue assessment and management were only available from one clinical site and were for the purpose of telephone triage (Table 4). Although more focused in nature, the 
assessment and management of fatigue outlined in these guidelines was congruent with those of the international cancer organisations although they do not explicitly identify exercise as an intervention. A protocol followed by three clinical sites recommended that patients with $B C$ who are experiencing fatigue should, where appropriate, receive a referral to rehabilitation specialists for guidance on rest and exercise. Of note, this protocol addressed the assessment and management of issues related to $\mathrm{BC}$ in general, rather than to fatigue specifically.

\section{CINV}

While acknowledging that they are separate phenomena (Grunberg, 2004), nausea and vomiting are discussed together within this context given the limited number of primary studies identified in the published literature for either toxicity. In total, six papers addressed either nausea or vomiting or both (primarily in $\mathrm{BC}$ ). However, only two of these papers discussed symptom management interventions. In 2008, Lee et al. conducted a secondary analysis of data from a longitudinal, multicentre, RCT that examined the effectiveness of a systematic exercise intervention during and after adjuvant $B C$ treatment. According to the authors, patients who exercised had significantly less intense nausea on completion of treatment than patients who did not exercise. Following their Cochrane review on the effect of herbal medicines on CRTs in patients with CRC, Wu et al. (2008) concluded that patients receiving Huangqi decoctions were less likely to develop CINV. However, the available studies were limited and of low quality. Only one study (Chou et al., 2007) addressed selfcare strategies for nausea ${ }^{4}$.

A number of cancer organisations developed CPGs/EBRs on CINV, including the ONS (Tipton et al., 2007, ONS, 2014), ESMO/MASCC (Roila et al., 2010), ASCO (Basch et al., 2011), UKONS (2013), and the NCCN (2014) (Table 5). CINV protocols were available from five clinical sites. Self-care advice only, was provided by a sixth site. In general, CPGs/EBRs focused more on the prevention and management of CINV than on assessment although the UKONS (2013) guideline did address assessment. The local protocols highlighted the importance of identifying the extent of the CINV, as well as the patients' hydration and nutritional status with a view to determining the grade of CINV and the subsequent action required. General agreement existed across the CPGs/EBRs and local protocols that CINV prevention is the first step. Similarly, the approach to treatment based on the emetogenic potential of the cytotoxic regimens is broadly consistent. For example, with the exception of UKONS, which did not focus on specific pharmacological treatments, all of the other organisations advocated that patients receiving highly emetic chemotherapy (HEC) regimens should receive the three-drug combination of a neurokinin 1 (NK1) antagonist, 5-hydroxytryptamine-3 (5HT3) receptor antagonist and dexamethasone with/without a benzodiazepine. According to the NCCN guideline (2014), an olanzapine based regimen may be considered as an alternative in this context. In terms of advice and self-care, general agreement existed around the importance of reviewing the prescribed anti-emetic regime with patients and counselling them regarding hydration and nutrition. The ONS (2007, 2014), ESMO/MASCC (2010) and three clinical sites guidelines suggested the potential benefit of non-pharmacological therapies such as relaxation/progressive muscle relaxation. The guidelines from ESMO/MASCC and ASCO considered the importance of approaches such as BT with desensitisation for anticipatory CINV.

\section{OM}

Two of the papers from the published literature review addressed OM. However, only one focused on symptom management. Peterson and colleagues (2009) evaluated the safety and efficacy of high 
and low dose recombinant human intestinal trefoil factor (rhITF) as a topical oral spray for the prevention and treatment of OM in patients receiving their first cycle of chemotherapy for CRC. According to the authors, high and low dose rhITF significantly reduced the incidence and severity of OM with particular improvements observed one to two weeks following treatment initiation. However, the low incidence of grade 3 and 4 OM in the study was noted and it was acknowledged that the benefits of this intervention could only be inferred for these high risk groups. Only one study (Chou et al., 2007) addressed self-care strategies for $\mathrm{OM}^{4}$.

Five cancer organisations developed CPGs/EBRs for OM, namely, ESMO (Peterson et al., 2011), UKONS (2013), MASCC/ISOO (International Society of Oral Oncology) (Lalla et al., 2014), and ONS (Harris et al., 2008). Symptom protocols were available from five clinical sites (Table 6). Self-care advice only was provided by a sixth site. The symptom protocols addressed the prevention, assessment, and management of OM, while the CPGs/EBRs primarily focused on prevention and management. The protocols emphasised the importance of conducting a comprehensive assessment to identify the severity of $\mathrm{OM}$, the presence of pain and/or other symptoms suggestive of local or systemic infection, dehydration, or compromised nutrition. With reference to management, in the main, broad agreement existed across the clinical site protocols and the CPGs/EBRs. Nonetheless, there were some variations. The use of oral care protocols and good oral hygiene in the context of OM was highlighted across all of the guidelines. However, the MASCC/ISOO (2014) guideline noted, that based on the available evidence, it is only possible to 'suggest' rather than 'recommend' the use of oral care protocols for OM prevention, while no guideline is recommended for the use of oral care protocols for $\mathrm{OM}$ treatment. In addition, although saline/sodium bicarbonate mouthwashes were recommended by other organisations (ONS, 2008, ESMO, 2011), MASCC/ISOO indicated that no guideline has been developed in this context due to insufficient and/or conflicting evidence. Some divergence was found with respect to the use of sucralfate mouthwash which is recommended by UKONS (2013) and four clinical sites. However, the MASCC/ISOO panel recommended against the use of sucralfate mouthwash for OM prevention or treatment based on a lack of benefit identified in the studies reviewed. In addition, the ONS and ESMO did not recommend the use of sucralfate for OM treatment associated with radiotherapy. Differences in recommendations were not just confined to those between international, local, and national guidelines. Although the MASCC/ISOO panel 'suggest' (p. 1457) that doxepin $0.5 \%$ mouthwash may be effective for OM associated pain, the ONS assigned this mouthwash to the category of 'effectiveness not established'.

\section{CIPN}

Only three of the papers from the published literature review addressed symptom management and one explored self-care strategies for CIPN. Wang et al. (2007) reported that oral glutamine significantly reduced CIPN incidence and severity in patients receiving oxaliplatin for metastatic CRC. However, following a literature review, Amara (2008) concluded that more high quality RCTs were needed to assess the safety and efficacy of oral glutamine before it could be recommended for CIPN prevention in patients receiving either high dose paclitaxel or oxaliplatin. Focusing only on premenopausal patients with BC, Loprinzi et al. (2008) noted the dearth of literature on effective treatments for CIPN.

Speck et al. (2012) reported that various self-care strategies were employed by women with BC to manage CIPN. While it was not possible to establish their effectiveness, the authors reported that patients focused on exercise, mindfulness, occupational therapy, and environmental planning to 
manage their CIPN. Although not described, Chou et al. (2007) noted that self-care strategies were used for CIPN by participants in their study ${ }^{4}$.

Three cancer organisations developed CPGs/EBRs relevant to CIPN, namely, EONS (2012), ASCO (Hershman et al., 2014) (focused on adult cancer survivors) and ONS (Aiello-Laws et al., 2009, ONS, 2014) (Table 7). A symptom management protocol for CIPN was only available from one clinical site and this protocol focused primarily on assessment as it was developed for telephone triage. All of the CPGs/EBRs focused more on CIPN management than assessment although EONS outlined some important considerations for assessment. No agent was recommended for CIPN prevention. However, for CIPN treatment, ASCO (2014) suggested that clinicians 'may offer' (p.23) duloxetine while the ONS considered duloxetine as 'likely to be effective'. ASCO, ONS, and EONS all identified a number of agents which should not be used for either the prevention or treatment of CIPN based on the evidence to date. However, given the limited options for managing CIPN, ASCO noted that some agents such as tricyclic antidepressants (TCAs) and gabapentin may be reasonable to try in selected patients following a discussion regarding the research to date, benefits, harms, costs, and patient preferences.

\section{Diarrhoea}

None of the articles from the published literature review addressed symptom management interventions or self-care strategies for diarrhoea (as a primary outcome) in patients receiving chemotherapy for any of the cancers. In contrast, diarrhoea was well addressed in the grey literature. Both ONS (Muehlbauer et al., 2009, ONS, 2014) and UKONS (2013) developed guidelines for diarrhoea, while protocols for diarrhoea were available from five clinical sites (Table 8). An additional clinical site provided self-care information only. UKONS addressed the initial assessment and management when patients present with diarrhoea as an emergency/unplanned admission. The ONS $(2009,2014)$ EBR identified interventions for both chemotherapy and radiotherapy-induced diarrhoea. Although the level of detail varied across the international and local guidelines, in general, consistency was found with reference to diarrhoea assessment and management. More specifically, all of the guidelines convey the importance of doing a comprehensive history to ascertain the extent of the diarrhoea, associated symptoms, hydration status, and treatment to date in order to determine the grade of diarrhoea and the subsequent action required. Loperamide was recommended for diarrhoea management across all of the guidelines and the importance of adherence was emphasised. The use of octreotide was recommended by both UKONS and ONS and three of the clinical sites protocols. However, although codeine phosphate was identified by UKONS (2013) and five clinical site protocols as a treatment for diarrhoea, it was not identified by ONS $(2009,2014)$ as an intervention that is 'recommended for practice', 'likely to be effective' or under 'expert opinion'. Also, ONS assigned budesonide to the 'effectiveness not established' category. However, budesonide does feature in the protocols of four clinical sites for the treatment of severe diarrhoea. In relation to self-care, broad agreement was found regarding the recommendations for hydration and nutrition.

\section{Constipation}

The published literature search located no articles on symptom management interventions for constipation (as a primary outcome) in patients receiving chemotherapy for any of the cancers. Only one study (Chou et al., 2007) addressed self-care strategies for constipation 4 . 
Only a limited number of guidelines and symptom protocols were available for constipation. These documents included the UKONS (2013) guideline for the initial management of constipation in patients who present as an emergency/unplanned admission and the ONS (Woolery et al., 2008, ONS, 2014) EBR for the prevention and management of constipation (Table 9). Only one clinical site provided a symptom protocol (telephone triage) for constipation, although information on self-care for this symptom was available from three additional sites. The guidance from ONS (2008) and UKONS (2013) and the clinical site protocol are broadly consistent with respect to constipation assessment. Likewise, the guidance for constipation management (including self-care) was similar. Specific information included the importance of a high fibre diet, adequate hydration, and adherence to prescribed medications. ONS $(2008,2014)$ identified a number of interventions that were considered to be 'likely to be effective' particularly in the context of opioid-induced constipation.

\section{PPE}

None of the articles retrieved through the published literature review addressed symptom management interventions or self-care strategies for PPE (as a primary outcome) in patients receiving chemotherapy for any of the cancers. No international CPGs were available for PPE. However, the ONS (2014) included this symptom in its EBR on skin reactions. The UKONS (2013) guideline focused on the initial management of patients with PPE who present as an emergency/unplanned admission (Table 10). A symptom management protocol for PPE was only available from one clinical site and this protocol focused on management only. The UKONS (2013) guideline recommended the provision of reassurance and reinforcing the importance of the skin care regime to patients experiencing grade 1 PPE while advising to withhold treatment for higher grade PPE. Consideration of pyridoxine was recommended by both UKONS and the clinical site protocol. However, this medication was assigned to the category of 'not recommended for practice' by ONS.

\section{FN and/or infection}

$\mathrm{FN}$ and infection are discussed together in this context given their close relationship and the limited number of studies identified for either toxicity. The published literature search located two review papers related to these toxicities. One paper focused on the use of supportive therapies for the management of FN and infection. A second paper discussed the evidence to date for Chinese herbal medicines (CHMs) for CRTs including leucopenia. O'Shaughnessy et al. (2007) discussed the use of colony stimulating factors (G-CSF) in patients receiving adjuvant treatment for BC. Based on the cumulative evidence across a number of different cancers, the authors pointed to the recent NCCN and ASCO guidelines which recommended routine use of CSFs for all patients receiving curative chemotherapy associated with $\mathrm{a} \geq 20 \%$ risk of $\mathrm{FN}$ or in high risk patients receiving curative chemotherapy associated with a $\leq 20 \%$ risk of FN. Following their Cochrane review which examined the effect of CHMs on CRTs in patients with CRC, Wu et al. (2008) concluded that extracts containing Huangqi had favourable effects on white blood cells, with respect to both total counts and in specific subcategories of immunocompetent lymphocytes. However, the available studies were limited and of low quality. None of the studies addressed self-care for FN or infection.

A number of CPGs/EBRs were available for FN and infection (Table 11). ASCO (Smith et al., 2006, Flowers et al., 2013) published guidelines on the use of CSFs and the antimicrobial prophylaxis and 
outpatient management of FN, respectively. Each year, the NCCN updates its guidelines for the prevention and treatment of cancer-related infections and their recommendations for myeloid growth factors. ESMO published guidelines for the management of FN (de Naurois et al., 2010) and the use of CSFs (Crawford, Caserta and Roila, 2010). Finally, ONS produced an EBR of interventions to prevent cancer-related infections (Zitella et al. 2006, ONS, 2014). The UKONS (2013) guideline focused on the initial assessment and management of patients presenting with neutropenic sepsis. Symptom protocols were developed by the clinical sites for the assessment and management of FN and/or neutropenic sepsis (Table 11). Overall, the guidance across all of these guidelines and protocols is consistent for both the assessment and management of patients presenting with $\mathrm{FN} /$ suspected neutropenic sepsis. All of the guidelines conveyed the importance of a comprehensive history and assessment and the administration of appropriate treatment based on the risk category identified. Broad consistency existed with respect to the prophylactic measures recommended for infection prevention.

\section{Pain}

Two papers from the published literature review focused on symptom management interventions for cancer pain. Both papers address exercise for pain in women receiving treatment for BC. Following their SR, Tatham and colleagues (2013) concluded that exercise may decrease shoulder pain related to $B C$ treatment. However, they noted that more high quality studies were needed. Due to the limited detail in the studies reviewed, the authors could only infer that a 'multi-factorial' (p.329) exercise programme may be beneficial. Following their multicentre RCT that examined the impact of exercise on physical functioning and symptoms such as 'bodily pain' (p.1823), Courneya et al. (2013) reported that a higher dose (50-60 minutes) of aerobic exercise was more beneficial for managing bodily pain associated with adjuvant BC treatment than either standard doses (25-30 minutes) or a combined dose of 50 to 60 minutes of aerobic and resistance exercise. Only one study (Chou et al., 2007) addressed self-care strategies for pain ${ }^{4}$.

Cancer pain is well addressed in the grey literature. Guidelines focusing on cancer pain were available from ESMO (Ripamonti et al., 2012), EONS (2012), ONS (Aiello-Laws et al., 2009, ONS, 2014) and NCCN (2014) (Table 12). Only one clinical site provided a pain management protocol. As this protocol was developed for telephone triage, its primary focus was pain assessment rather than pain management interventions (Table 12). Brief self-care advice was available from another clinical site. A general consensus was found across all of the international guidelines regarding the approach to pain assessment and management. More specifically, the guidelines highlighted the importance of undertaking a comprehensive history and assessment to examine the physical and psychosocial impact of pain. Many factors require consideration in order to determine the most appropriate interventions including but not exclusive to the type and severity of pain, whether it is acute, chronic, or breakthrough pain, the patient's diagnosis and treatment to date, comorbidities and psychosocial factors. Recommendations included the use of both pharmacological and nonpharmacological strategies and the importance of managing common side effects such as constipation and nausea and vomiting. These guidelines were broadly in line with the World Health Organisation (WHO) analgesic ladder which advocates a sequential progression from non-opioids to weak opioids to strong opioids. However, while acknowledging that the WHO ladder has served as an excellent teaching tool, NCCN suggested the use of opioids for all levels of pain including mild 
pain. The importance of providing psychosocial support and education to the patient and family was recommended.

\section{Discussion}

To our knowledge this scoping review is the first of its kind to examine the literature and international, national, and relevant local guidelines for the assessment and management of the most common CRTs, namely, fatigue, nausea, vomiting, OM, CIPN, diarrhoea, constipation, FN, infection, $\mathrm{PPE}$, and pain in people with $\mathrm{BC}, \mathrm{CRC}, \mathrm{NHL}$, or $\mathrm{HL}$. A number of observations are evident from this review. Of all of the symptoms included in the review, fatigue is the most frequently studied with over half of the published articles addressing this symptom. However, the papers primarily focused on fatigue in women with BC. Only one study (Courneya et al., 2009) examined the impact of exercise in patients with lymphoma. With the exception of self-care (Spichiger et al. 2012), none of the studies examined interventions for fatigue in patients with CRC. Given the benefits of exercise identified in the studies of BC in this review and more recently (Mishra et al., 2014), similar studies in patients with CRC and lymphomas are warranted. In the meantime, given the relatively low engagement in exercise among oncology patients receiving chemotherapy (Spichiger et al., 2012) and among cancer survivors (Forbes et al., 2015), clinicians should counsel patients on the benefits of exercise as tolerated.

The use of aerobic and resistance exercises are supported by ASCO, ONS, and NCCN as interventions for fatigue. The other interventions supported by these organisations and the published literature (Wanchai et al., 2011) include the management of associated symptoms and treatable factors, education and counselling, energy conservation measures, CBT/BT, sleep therapy, psychoeducational therapies, $\mathrm{CT}$, and nutritional advice. However, it is likely that these interventions are only effective if assessment and management of fatigue is undertaken regularly throughout patients' treatment and not just at the outset (Spichiger et al., 2012). While we cannot confirm that the lack of protocols from the clinical sites necessarily indicates that fatigue assessment and management is not ongoing, it does suggest that this symptom may not be prioritised to the same extent as others for which protocols do exist. If this is the case, it needs to be redressed given that fatigue is one of the most frequently reported CRTs (Goldstein et al., 2012, Wang et al., 2014) and is associated with significant morbidity and utilization of healthcare resources (Goldstein et al., 2012).

In contrast to fatigue, CINV was more likely to be addressed by clinical site protocols than the published literature. Both nausea and vomiting are well addressed by CPGs/EBRs including ONS, ESMO/MASCC, ASCO and NCCN guidelines. General consensus exists across these guidelines with respect to the anti-emetics recommended, with all of the organisations recommending that patients receiving HEC should receive a similar three-drug combination of anti-emetic therapy. The self-care measures recommended in the clinical site protocols are broadly consistent with those in the CPGs.

Only two papers in the review of the published literature focused on OM. However, OM guidelines are available from a number of cancer organisations and clinical sites. While a general consensus was found across all of the guidelines and protocols with respect to the assessment, management, and prevention of $\mathrm{OM}$, some differences were identified in the recommendations. Although the MASCC/ISOO (2014) panel do not actively recommend against the use of oral care protocols or saline/sodium bicarbonate mouthwashes, they appear less compelled by the evidence for these 
interventions for the prevention of OM across all cancer treatments. However, the MASCC/ISOO (2014) panel did recommend against the use of sucralfate mouthwash for the prevention or treatment of OM. In addition, the ONS $(2008,2014)$ recommended against the use of sucralfate as did ESMO for the treatment of OM associated with radiotherapy. Clinical protocols from four clinical sites and the UKONS (2013) guideline on OM suggest that sucralfate was still recommended for OM. As the international guidelines were published more recently, it is conceivable that national and local protocols had not been updated to reflect these recommendations. Differences in recommendations were not just confined to those between international, national and local guidelines as evidenced by the differing recommendations from MASCC/ISOO and the ONS on the effectiveness of doxepin $0.5 \%$ mouthwash for $\mathrm{OM}$ associated pain. While differing conclusions may be based on the availability of data at the time of the respective guideline publications, it does underscore the challenges encountered by clinicians when updating local protocols.

CIPN was the subject of three papers in the review of the published literature. However, more studies are needed to identify effective approaches to prevent and manage this CRT. Although CPGs/EBRs were available from three international organisations, a CIPN symptom protocol was available from only one clinical site. Again, this finding may be due to the fact that the CPGs/EBRs are more recent. It may reflect the limited options available for the prevention and/or treatment of CIPN. In addition to duloxetine, ASCO suggested that TCAs and gabapentin may be reasonable to try in selected patients. The EONS (2012) guideline may be of particular benefit to oncology nurses for the purpose of educating patients about beneficial CIPN self-care strategies.

The published literature search located no papers focused on symptom management for diarrhoea, constipation, or PPE. Although diarrhoea is addressed by only ONS $(2009,2014)$ and UKONS $(2013)$, symptom protocols for diarrhoea were provided by five clinical sites. In general, consensus was found across the guidelines and local protocols with respect to diarrhoea assessment and management. These recommendations were consistent with the guideline published by ASCO (Benson et al., 2004). Two particular differences were noted among the local and national guidelines when compared to the ONS recommendations. Although codeine phosphate was identified by UKONS and the five clinical site protocols as a treatment for diarrhoea, it was not identified as an intervention for diarrhoea by ONS (2009). Also, in 2009, ONS assigned budesonide to the 'effectiveness not established' category. However, this medication features in the symptom management protocols of four clinical sites for the treatment of severe diarrhoea. This review found a limited number of guidelines and symptom protocols available on constipation. Only one clinical site provided a symptom protocol although information related to self-care for constipation was available from four clinical sites. Similarly, a dearth of CPGs/EBRs focused on symptom management for PPE and perhaps not unrelated a symptom management protocol was provided by only one clinical site. Of note, consideration of pyridoxine was recommended by both UKONS (2013) and a clinical site protocol. However, this medication was assigned to the category of 'not recommended for practice' by the ONS.

FN and infection was the subject of only two papers from the published literature review. Both papers were literature reviews and one was a Cochrane review (Wu et al., 2008). This finding is likely due to the inclusion criteria which focused exclusively on the symptom management and self-care strategies for $\mathrm{FN}$ and infection in patients diagnosed with $\mathrm{BC}, \mathrm{CRC}, \mathrm{NHL}$, or $\mathrm{HL}$. Most likely reflecting the potentially life threatening nature of infection in patients with cancer (Pathak et al., 2015), a 
number of CPGs/EBRs address FN and infection. Symptom protocols were developed by the clinical sites and, in the main, the guidance across all of these guidelines and protocols is consistent for both the assessment and management of patients presenting with $\mathrm{FN} /$ suspected neutropenic sepsis. The guidelines all conveyed the importance of a comprehensive history and assessment and the delivery of appropriate treatment based on the risk category identified. Broad consistency was found with respect to the prophylactic measures recommended for infection prevention.

The review of the published literature located two papers on symptom management interventions for pain. Both papers focused on exercise for pain in women receiving treatment for $\mathrm{BC}$ and while this intervention appears promising, more high quality studies are needed. Overall, pain is well addressed by CPGs/EBRs. In contrast to this finding, only one clinical site provided a symptom management protocol for pain. As this protocol was developed for the purpose of telephone triage, a greater focus was placed on the assessment of pain rather than interventions for pain management. Brief self-care advice was available from another clinical site. A general consensus was found across all of the international guidelines regarding the approach to pain assessment and management. Recommendations included the use of both pharmacological and nonpharmacological strategies and the importance of managing common side effects. The guidelines are broadly in line with the World Health Organisation (WHO) analgesic ladder which advocates a sequential progression from non-opioids to weak opioids to strong opioids. However, more recently the NCCN (2014) suggested the use of opioids for all levels of pain including mild pain. The importance of providing psychosocial support and education to the patient and family was recommended.

\section{Limitations}

The main limitation of this review is the lack of empirical research retrieved for the assessment and management of diarrhoea, constipation and PPE, in particular. This deficit may be due to the fact that the published literature search was confined to those studies where symptom assessment, management, or self-care was identified as a primary outcome. In addition, limiting the search to three databases and including only those studies published in English and undertaken over the previous ten year period (2004-2014) may explain the dearth of studies for these symptoms. The conduct of a recent literature review ${ }^{3}$ and time constraints imposed by internal study deadlines informed the decision to limit the search to three databases and to include only those studies conducted in the previous ten years. That said, this scoping review includes seven literature reviews (including four SR) and recently updated CPGs/EBRs from leading international medical and nursing cancer organisations. The studies included in this review were not critically appraised as a scoping review does not set out to determine the quality of evidence, rather it seeks to examine as comprehensively as possible the published and grey literature relevant to the research question (Arksey and O' Malley, 2005). Finally, information on symptom management protocols and self-care guidance was available from just over $40 \%$ of the participating clinical sites. Of note, while this scoping review included a consultation exercise with clinicians and patients at each of the participating clinical sites and with clinicians working with National Health Service (NHS) 24) (Scotland's national telehealth and telecare organisation), the data from this exercise are not reported here due to the word count limit. 


\section{Conclusions}

Guidance for symptom management of the most common CRTs varies across the published and grey literature. A need exists for more empirical research on symptom management for PPE, diarrhoea, constipation and CIPN. In addition, empirical research studies of symptom management interventions are needed in patients with CRC and lymphomas. Finally, research is needed on the efficacy of self-care strategies in patients with BC, CRC, HL and NHL. Relative to other symptoms, PPE, diarrhoea, and constipation are less likely to be addressed by CPGs/EBRs. With a few exceptions, a broad consistency exists across CPGs/EBRs and local guidelines on the assessment and management of commonly occurring CRTs.

Data in this manuscript were collected by the eSMART Collaborative Study Group [Lead investigator: Professor Roma Maguire, University of Surrey]. The eSMART project has received funding from the European Union's Seventh Framework Programme for research, technological development and demonstration under grant agreement No. 602289. The contents of this publication are solely the responsibility of the authors and do not necessarily represent the official views of the funding organisation. 


\section{References}

Aiello-Laws, L., Reynolds, J., Deizer, N., Peterson, M., Ameringer, S., Bakitas, M., 2009. Putting evidence into practice: what are the pharmacologic interventions for nociceptive and neuropathic cancer pain in adults?. Clin. J. Oncol. Nurs. 13, 649-655.

Amara, S., 2008. Oral glutamine for the prevention of chemotherapy-induced peripheral neuropathy. Ann Pharmacother. 42, 1481-1485.

American Society of Clinical Oncology, 2014. Screening, assessment, and management of fatigue in adult survivors of cancer. http://www.asco.org/adaptations/fatigue (accessed 16.04.14).

Arksey, H. and O'Malley, L. (2005) 'Scoping Studies: towards a methodological framework', International Journal of Social Research Methodology, 8, 19-32.

Basch, E., Prestrud, A., Hesketh, P., Kris, M., Feyer, P., Somerfield, M., Chesney, M., Clark-Snow, R., Flaherty, A.M., Freundlich, B., Morrow, G., 2011. Antiemetics: American Society of Clinical Oncology Clinical Practice Guideline Update. J. Clin. Oncol. 29, 4189-4197.

Benson, A.B. III, Ajani, J.A., Catalano, R.B., Engelking, C., Kornblau, S.M., Martenson, J.A. Jr, McCallum, R., Mitchell, E.P., O'Dorisio, T.M., Vokes, E.E., Wadler S., 2004. Recommended guidelines for the treatment of cancer treatment-induced diarrhea. Clin. J. Oncol. Nurs. 22, 2918-2926.

Berger, A., Kuhn, B., Farr, L., Von Essen, S., Chamberlain, J., Lynch, J., Agrawal, S., 2009. One-Year outcomes of a behavioural therapy intervention trial on sleep quality and cancer-related fatigue. J. Clin. Oncol. 27, 6033-6040.

Blackhall, K., Ker, K., 2007. Finding studies for inclusion in systematic reviews of interventions for injury prevention - the importance of grey and unpublished literature. Inj. Prev. 13, 359.

Bower, J.E., Bak, K., Berger, A., Breitbart, W., Escalante, C.P., Ganz, P.A., Schnipper, H.H., Lacchetti, C., Ligibel, J.A., Lyman, G.H., Ogaily, M.S., Pirl, W.F., Jacobsen, P.B., 2014. Screening, assessment, and management of fatigue in adult survivors of cancer: an American Society of Clinical oncology clinical practice guideline adaptation. J. Clin. Oncol. 32, 1840-1850.

Chou, F., Dodd, M., Abrams, D., Padilla, G., 2007. Symptoms, self-care, and quality of life of Chinese American patients with cancer. Oncol. Nurs. Forum. 34, 1162-1167.

Courneya, K., Segal, R., Mackey, J., Gelmon, K., Reid, R., Friedenreich, C., Ladha, A., Proulx, C., Vallance, J., Lane, K. Yasui, Y., McKenzie, D, 2007a. Effects of aerobic and resistance exercise in BC patients receiving adjuvant chemotherapy: a multicenter randomized controlled trial. J. Clin. Oncol. 25, 4396-4404.

Courneya, K., Segal, R., Gelmon, K., Reid, R., Mackey, J., Friedenreich, C., Proulx, C., Lane, K., Ladha, A., Vallance, J., Liu, Q., Yasui, Y., McKenzie, D., 2007b. Six-month follow-up of patient-related outcomes in a randomized controlled trial of exercise training during $B C$ chemotherapy. Cancer Epidemiol. Biomarkers Prev. 16, 2572-2578. 
Courneya, K., Sellar, C., Stevinson, C., McNeely, M., Peddle, C., Friedenreich, C., Tankel, K., Basi, S., Chua, N., Mazurek, A., Reiman, T., 2009. Randomized controlled trial of the effects of aerobic exercise on physical functioning and quality of life in lymphoma patients. J. Clin. Oncol. 27, 46054612.

Courneya, K., McKenzine, D., Mackey, J., Gelmon, K., Friedenreich, C., Yasui, Y., Reid, R., Cook, D., Jespersen, D., Proulx, C., Dolan, L., Forbes, C., Wooding, E., Trinh, L., Segal, R., 2013. Effects of exercise dose and type during $\mathrm{BC}$ chemotherapy: multicenter randomized trial. J. Natl. Cancer Inst. 105, 1821-1832.

Crawford, J., Caserta, C., Roila, F., 2010. Hematopoietic growth factors: ESMO Clinical Practice Guidelines for the applications. Ann. Oncol. 21, 248-251.

de Naurois, J., Novitzky-Basso, I., Gill, M.J., Marti Marti, F., Cullen, M.H., Roila, F., 2010. Management of febrile neutropenia: ESMO clinical practice guidelines. Ann. Oncol. 21, 252-256.

Dibble, S., Casey, K., Nussey, B., Israel, J., Luce, J., 2004. Chemotherapy-induced vomiting in women treated for BC. Oncol. Nurs. Forum. 31, 1-7.

European Oncology Nursing Society, 2012. Pain.

http://www.cancernurse.eu/education/europeps.html (accessed 16.04.14).

European Oncology Nursing Society, 2012. Peripheral neuropathy.

http://www.cancernurse.eu/education/europeps.html (accessed 16.04.14).

European Oncology Nursing Society, 2013. Breakthrough cancer pain guidelines 2013.

http://www.cancernurse.eu/education/breakthroughcancerpain.html (accessed 16.04.14).

Flowers, C.R., Seidenfeld, J., Bow, E.J., Karten, C., Gleason, C., Hawley, D.K., Kuderer, N.M., Langston, A.A., Marr, K.A., Rolston, K.V., Ramsey, S.D., 2013. Antimicrobial prophylaxis and outpatient management of fever and neutropenia in adults treated for malignancy: American Society of Clinical Oncology clinical practice guideline. Clin. J. Oncol. Nurs. 31, 794-810.

Forbes, C.C., Blanchard, C.M., Mummery, W.K., Courneya, K., 2015. Prevalence and correlates of strength exercise among breast, prostate, and colorectal cancer survivors. Oncol. Nurs. Forum. 42, 118-127.

Gibson, F., Aldiss, S., Taylor, R.M., Maguire, R., Kearney, N., 2009. Involving health professionals in the development of an advanced symptom management system for young people: the ASyMS-YG study. Eur. J. Cancer. 13, 187-192.

Gibson, F., Aldiss, S., Taylor, R.M., Maguire, R., McCann, L., Sage, M., Kearney, N., 2010. Utilization of the Medical Research Council evaluation framework in the development of technology for symptom management: the ASyMS-YG Study. Cancer Nurs. 33, 343-352.

Goldstein, D., Bennett, B., Webber, K., Boyle, F., de Souza, P., Wilcken, N., Scott, E., Toppler, R., Murie, P., O’Malley, L., McCourt, J., Friedlander, M., Hickie, I., Llyod, A., 2012. Cancer-related fatigue in women with BC: outcomes of a 5-year prospective cohort study. J. Clin. Oncol. 30, 1805-1812. 
Grunberg, S.M., Deuson, R.R., Mavros, P., Geling, O., Hansen, M., Cruciani, G., Daniele, B., De Pouvourville, G., Rubenstein, E.B., Daugaard, G., 2004. Incidence of chemotherapy-induced nausea and emesis after modern antiemetics. Cancer. 100, 2261-2268.

Harris, D.J., Eilers, J., Harriman, A., Cashavelly, B.J., Maxwell, C., 2008. Evidence-based interventions for the management of oral mucositis: putting evidence into practice. Clin. J. Oncol. Nurs. 12, 141152.

Hershman, D., Lacchetti, C., Dworkin, R., Lavoie Smith, E., Bleeker, J., Cavaletti, G., Chauhan, C., Gavin, P., Lavino, A., Lustberg, M., Paice, J., Schneider, B., Smith, M.L., Smith, T., Terstriep, S., Wagner-Johnston, N., Bak, K., Loprinzi, C., 2014. Prevention and management of chemotherapyinduced peripheral neuropathy in survivors of adult cancers: American Society of Clinical Oncology Clinical Practice Guideline. J. Clin. Oncol. 32, 1941-1970.

Kearney, N., Kidd, L., Miller, M., Sage, M., Khorrami, J., McGee, M., Cassidy, J., Niven, J., Gray P., 2006. Utilising handheld computers to monitor and support patients receiving chemotherapy: results of a UK-based feasibility study. Supp. Care Cancer. 14, 742-752.

Kearney, N., McCann, L., Norrie, J., Taylor, L., Gray, P., McGee-Lennon, M., Sage, M., Miller, M., Maguire, R., 2009. Evaluation of a mobile phone

based, advanced symptom management system (ASyMS) in the management of chemotherapyrelated toxicity. Supp. Care Cancer. 17, 437-444.

Kirshbaum, M., 2006. A review of the benefits of whole body exercise during and after treatment for BC. J. Clin. Oncol. 16, 104-121.

Lalla, R.V., Bowen, J., Barasch, A., Elting, L., Epstein, J., Keefe, D.M., McGuire, D.B., Migliorati, C., Nicolatou-Galitis, O., Peterson, D.E., Raber-Durlacher, J.E., Sonis, S.T., Elad, S., 2014. MASCC/ISOO clinical practice guidelines for the management of mucositis secondary to cancer therapy. Cancer. $120,1453-1461$.

Lee, J., Dodd, M., Dibble, S., Abrams, D., 2008. Nausea at the end of adjuvant cancer treatment in relation to exercise during treatment in patients with BC. Oncol. Nurs. Forum. 35, 830-835.

Ligibel, J., Partridge, A., Giobbie-Hurder, A., Campbell, N., Shockro, L., Salinadri, T., Winer, E., 2010. Physical and psychological outcomes among women in a telephone-based exercise intervention during adjuvant therapy for early stage BC. J. Womens Health. 19, 1553-1559.

Loprinzi, C., Wolf, S., Barton, D., Laack, N., 2008. Symptom management in premenopausal patients with BC. Lancet Oncol. 9, 993-1001.

Maguire, R., Cowie, J., Leadbetter, C., McCall, K., Swingler, K., McCann, L., Kearney, N., 2009. The development of a side effect risk assessment tool (ASyMSC-SERAT) for use in patients with BC undergoing adjuvant chemotherapy. J. Res. Nurs. 14, 27-40.

Maguire, R., Ream, E., Richardson, A., Connaghan, J., Johnston, B., Kotronoulas, G., Pedersen, V., McPhelim, J., Pattison, N., Smith, A., Webster, L., Taylor, A., Kearney N., 2015. Development of a novel remote patient monitoring system: The advanced symptom management system for 
radiotherapy to improve the symptom experience of patients with lung cancer receiving radiotherapy. Cancer Nurs. 38, E37-E47.

Mishra, S.I., Scherer, R.W., Snyder, C., Geigle, P., Gotay C., 2014. Are exercise programs effective for improving health-related quality of life among cancer survivors? A systematic review and metaanalysis. Oncol. Nurs. Forum. 41, 326-342.

Mitchell, S.A., Beck, S.L., Hood, L.E., Moore, K., Tanner, E. R., 2007. Putting evidence into practice: evidence-based interventions for fatigue during and following cancer and its treatment. Clin. J. Oncol. Nurs. 11, 99-113.

Muehlbauer, P., Thorpe, D., Davis, A., Drabot, R., Rawlings, B., Kiker, E., 2009. Putting evidence into practice: evidence-based interventions to prevent, manage, and treat chemotherapy and radiotherapy-induced diarrhea. Clin. J. Oncol. Nurs. 13, 336-341.

Munir, F., Kalawsky, K., Lawrence, C., Yarker, J., Haslam., C., Ahmed, S., 2011. Cognitive intervention for BC patients undergoing adjuvant chemotherapy: a needs analysis. Cancer Nurs. 34, 385-392.

Nakaguchi, T., Okuyama, T., Uchida, M., Ito, Y., Komatsu, H., Wada, M., Akechi, T., 2013. Oncology nurses' recognition of supportive care needs and symptoms of their patients undergoing chemotherapy. Jpn. J. Clin. Oncol. 43, 369-376.

National Cancer Institute, 2010. National Cancer Institute Common Toxicity Criteria. http://ctep.cancer.gov/protocolDevelopment/electronic_applications/ctc.htm. (accessed 21.02.14).

National Comprehensive Cancer Network, 2014. NCCN Clinical Practice Guidelines in Oncology: myeloid growth factors. http://www.nccn.org/professionals/physician_gls/f_guidelines.asp (accessed 10.04.14).

National Comprehensive Cancer Network, 2014. NCCN Clinical Practice Guidelines in Oncology: Adult cancer pain. http://www.nccn.org/professionals/physician_gls/f_guidelines.asp (accessed 10.04.14).

National Comprehensive Cancer Network, 2014. NCCN Clinical Practice Guidelines in Oncology: Antiemesis. http://www.nccn.org/professionals/physician_gls/f_guidelines.asp (accessed 10.04.14). National Comprehensive Cancer Network, 2014. NCCN Clinical Practice Guidelines in Oncology: cancer-related fatigue. http://www.nccn.org/professionals/physician_gls/f_guidelines.asp (accessed 10.04.14).

National Comprehensive Cancer Network, 2014. NCCN Clinical Practice Guidelines in Oncology: prevention and treatment of cancer-related infections. http://www.nccn.org/professionals/physician_gls/f_guidelines.asp (accessed 12.04.14).

O'Shaughnessy, J., 2007. Management of febrile neutropenia and cardiac toxicity in the adjuvant treatment of BC. Clin. Breast Cancer, 8, 11-21.

Oncology Nursing Society, 2014. Putting evidence into practice (PEP guidelines). https://www.ons.org/practice-resources/pep (accessed 10.04.14). 
Pathak, R., Giri, S., Aryal, M.R., Karmacharya, P., Bhatt, V.R., Martin, M.G., 2015. Mortality, length of stay, and health care costs of febrile neutropenia-related hospitalizations among patients with $B C$ in the United States. Supp. Care Cancer. 23, 615-617.

Peterson, D.E., Barker, N.P., Akhmaullina, L.I., Rodionova, I., Sherman, N.Z., Davidenko, I.S., Rakovskaya, G.N., Gotovkin, E.A., Shinkarev, S.A., Kopp, M.V., Kulikov, M.P., Moiseyenko, V.M., Gertner, J.M., Firsoy, I., Tueleva, T., Yarosh, A., Woon, C.W., 2009. Phase II, randomised, doubleblind, placebo-controlled study of recombinant human intestinal trefoil factor oral spray for prevention of oral mucositis in patients with colorectal cancer who are receiving fluorouracil-based chemotherapy, J Clin Oncol. 27, 4333-4338.

Peterson, D.E., Bensadoun, R.-J., Roila, F., 2011. Management of oral and gastrointestinal mucositis: ESMO Clinical Practice Guidelines. Ann. Oncol. 6, 78-84.

Ripamonti, C.I., Santini, D., Maranzano, E., Berti, M., Roila, F., 2012. Management of cancer pain: ESMO clinical practice guidelines. Ann. Oncol. 23, 139-154.

Roila, F., Herrstedt, J., Aapro, M., Gralla, R.J., Einhorn, L.H., Ballatori, E., Bria, E., Clark-Snow, R.A., Espersen, B.T., Feyer, P., Grunberg, S.M., Hesketh, P.J., Jordan, K., Kris, M.G., Maranzano, E., Molassiotis, A., Morrow, G., Olver, I., Rapoport, B.L., Rittenberg, C., Saito, M., Tonato, M., Warr, D., 2010. Guideline update for MASCC and ESMO in the prevention of chemotherapy- and radiotherapyinduced nausea and vomiting: results of the Perugia consensus conference. Ann. Oncol. 21, 232-243.

Smith, T., Khatcheressian, J., Lyman, G., Ozer, H., Armitage, J., Balducci, L., Bennett, C.L., Cantor, S.B., Crawford, J., Cross, S., Demetri, G., Desch, C., Pizzo, P., Schiffer, C., Schwartzberg, L., Somerfield, M., Somlo, G., Wade, J.C., Wade J.L., Winn, R., Wozniak, A., Wolff, A., 2006. 2006 Update of recommendations for the use of white blood cell growth factors: an evidence-based clinical practice guideline. J. Clin. Oncol. 24, 3187-3205.

Smithies, M., Bettger-Hahn, M., Forchuk, C., Brackstone, M., 2009. Telephone contact intervention in women undergoing treatment of BC. Can Oncol Nurs J. 19, 122-128.

Speck, R., DeMichele, A., Farrar, J., Hennessy, S., Mao, J., Stineman, M., Barg, F., 2012. Scope of symptoms of self-management strategies for chemotherapy-induced peripheral neuropathy in $B C$ patients. Supp. Care Cancer. 20, 2433-2439.

Spichiger, E., Rieder, E., M-F, C., Kesselring, A., 2012. Fatigue in patients undergoing chemotherapy, their self-care and the role of health professionals: a qualitative study. Eur J Oncol Nurs. 16, 165-171.

Tatham, B., Smith, J., Cheifetz, O., Gillespie, J., Snowden, K., Temsey, J., Vandenberk, L., 2013. The efficacy of exercise therapy in reducing shoulder pain related to BC: A systematic review. Physiother Can. 65, 321-330.

Tipton, J.M., McDaniel, R.W., Barbour, L., Johnston, M.P., Kayne, M., LeRoy, P., Ripple, M.L., 2007. Putting evidence into practice: evidence-based interventions to prevent, manage, and treat chemotherapy-induced nausea and vomiting. Clin. J. Oncol. Nurs. 11, 69-78. 
UK Department of Health, 2011. Typology of Supportive Evidence.

http://webarchive.nationalarchives.gov.uk/+/www.dh.gov.uk/en/publicationsandstatistics/publicati ons/publicationspolicyandguidance/browsable/DH_4901347 (accessed 04.04.14).

UK Oncology Nursing Society (UKONS), 2013. Acute oncology initial management guidelines. www.ukons.org (accessed 11.04.14).

Wanchai, A., Armer, J. and Stewart, B., 2011. Non-pharmacologic supportive strategies to promote quality of life in patients experiencing cancer-related fatigue: a systematic review. Clin. J. Oncol. Nurs. 15, 203-214.

Wang, W.S., Lin, J.K., Lin, T.C., Chen, W.S., Jiang, J.K., Wang, H.S., Chiou, T.J., Liu, J.H., Yen, C.C., Chen P.M., 2007. Oral Glutamine is effective for preventing oxaliplatin-induced neuropathy in colorectal cancer patients. Oncologist. 12, 312-319.

Woolery, M., Bisanz, A., Lyons, H.F., Gaido, L., Yenulevich, M., Fulton, M.S., McMillan, S., 2008. Putting evidence into practice: evidence-based interventions for the prevention and management of constipation in patients with cancer. Clin. J. Oncol. Nurs. 12, 317-337.

Wu, T., Munro, A., Guanjian, L., Liu, G., 2008. Chinese medical herbs for chemotherapy side effects in colorectal cancer patients. Cochrane Database Syst Rev. 1.

Wu, H-S, Dodd, M., Cho, M. 2008. Patterns of fatigue and effect of exercise in patients receiving chemotherapy for BC. Oncol Nurs Forum. 35, 90-99.

Zitella, L.J., Friese, C.R., Hauser, J., Gobel, B.H., Woolery, M., O'Leary, C., Andrews, F.A., 2006. Putting evidence into practice: prevention of infection. Clin. J. Oncol. Nurs. 10, 739-750. 
Appendix 1

\title{
String 1
}

Assessment OR evaluation OR measurement OR tool OR questionnaire OR "outcome measure" OR "symptom management" OR "symptom control" OR "Symptom Assessment"[Mesh] OR "Outcome and Process Assessment (Health Care)"[Mesh] OR "Self-Assessment"[Mesh]) OR "Evaluation Studies as Topic"[Mesh] OR "Questionnaires"[Mesh] OR "Outcome Assessment (Health Care)"[Mesh] OR "patient reported outcome measur\$"

\author{
String 2 \\ "BC" OR "breast tumor" OR "colorectal cancer" OR "colon cancer" OR "rectal cancer" OR \\ lymphoma OR "non-Hodgkin lymphoma" OR "Hodgkin's disease" OR "Breast Neoplasms"[Mesh] \\ OR "Colorectal Neoplasms"[Mesh] OR "Colonic Neoplasms"[Mesh] OR "Rectal Neoplasms"[Mesh] \\ OR "Lymphoma"[Mesh] OR "Lymphoma, Non-Hodgkin"[Mesh] OR "Hodgkin Disease"[Mesh]

\section{String 3} \\ Chemotherapy OR chemotoxicity OR cytotoxic agents OR treatment regiment OR "Drug \\ Therapy"[Mesh] OR "drug therapy" [Subheading \\ String 4 \\ Self-care OR self-management OR self-efficacy OR self-assessment OR "Self Care"[Mesh] OR "Self \\ Efficacy"[Mesh] OR "Self-Assessment"[Mesh]
}

\section{String 5}

Chemotherapy AND (symptom* OR side effect* OR adverse effect*) OR Nausea OR vomiting OR diarrhea OR constipation OR Stomatitis OR oral mucositis OR peripheral neuropathy OR alterations in sensation OR hand-foot syndrome OR febrile neutropenia OR fever OR infection OR fatigue OR tiredness OR exhaustion OR pain OR "Peripheral Nervous System Diseases"[Mesh] OR "Hand-Foot Syndrome"[Mesh] OR "Febrile Neutropenia"[Mesh] OR "Chemotherapy-Induced Febrile Neutropenia"[Mesh] OR "Fever"[Mesh] OR "Infection"[Mesh] OR "Fatigue"[Mesh] OR "Pain"[Mesh] OR "Nausea"[Mesh] OR "Stomatitis"[Mesh]

\section{Final Search}

chemotherapy AND (symptom* OR side effect* OR adverse effect*) OR nausea OR vomiting OR diarrhea OR constipation OR stomatitis OR oral mucositis OR peripheral neuropathy OR "alterations in sensation" OR hand-foot syndrome OR "febrile neutropenia" OR fever OR infection OR fatigue OR tiredness OR exhaustion OR pain OR "Peripheral Nervous System Diseases"[Mesh] OR "Hand-Foot Syndrome"[Mesh] OR "Febrile Neutropenia"[Mesh] OR "Chemotherapy-Induced Febrile Neutropenia"[Mesh] OR "Fever"[Mesh] OR "Infection"[Mesh] OR "Fatigue"[Mesh] OR "Pain"[Mesh] OR "Nausea"[Mesh] OR "Stomatitis"[Mesh] AND "BC" OR "breast tumor" OR "colorectal cancer" OR "colon cancer" OR "rectal cancer" OR lymphoma OR "non-Hodgkin lymphoma" OR "Hodgkin's disease" OR "Breast Neoplasms"[Mesh] OR "Colorectal Neoplasms"[Mesh] OR "Colonic Neoplasms"[Mesh] OR "Rectal Neoplasms"[Mesh] OR "Lymphoma"[Mesh] OR "Lymphoma, Non-Hodgkin"[Mesh] OR "Hodgkin Disease"[Mesh] AND assessment OR evaluation OR measurement OR tool OR questionnaire OR "outcome measure" OR "symptom management" OR "symptom control"OR "Symptom Assessment"[Mesh] OR "Outcome and Process Assessment (Health Care)"[Mesh] OR "Self-Assessment" [Mesh] OR "Evaluation Studies as Topic"[Mesh] OR "Questionnaires"[Mesh] OR "Outcome Assessment (Health Care)"[Mesh] AND chemotherapy OR chemotoxicity OR cytotoxic agents OR treatment regimens OR "Drug Therapy"[Mesh] OR "drug therapy"[Subheading] AND self-care OR self-management OR self-efficacy OR self-assessment OR "Self Care"[Mesh] OR "Self Efficacy"[Mesh] OR "SelfAssessment"[Mesh]

Figure 1. Example of database search (PubMed) 


\section{Appendix 2}

Table 2. Description of published papers $(\mathbf{N}=27)$ included in review

\begin{tabular}{|c|c|c|c|c|}
\hline Author/Year & Sample size/Diagnosis & Study Design* & Study Aim/Intervention/Instrument & Study Findings and Limitations \\
\hline \multicolumn{5}{|c|}{ Fatigue } \\
\hline $\begin{array}{l}\text { Berger et al. } \\
\text { (2009): }\end{array}$ & $\begin{array}{l}\mathrm{N}=219 ; \text { patients with } \\
\text { stages } 1 \text { to } 111 \mathrm{BC} \\
\text { commencing adjuvant } \\
\text { chemotherapy. }\end{array}$ & $\begin{array}{l}\text { RCT (Two } \\
\text { centres) } \\
\text { (B1) }\end{array}$ & $\begin{array}{l}\text { To determine one year outcomes of a four } \\
\text { component behavioral therapy (BT) sleep } \\
\text { intervention vs a healthy eating control (HEC) on } \\
\text { fatigue (primary endpoint). } \\
\text { BT plan including stimulus control, modified sleep } \\
\text { restriction, relaxation therapy, and sleep hygiene. } \\
\text { Instrument(s): Piper Fatigue Scale }\end{array}$ & $\begin{array}{l}\text { BT (Individualized Sleep Promotion Plan } \\
\text { [ISPP C]) improved global sleep quality but } \\
\text { did not impact fatigue outcomes. } \\
\text { Limitations: milder fatigue levels than } \\
\text { anticipated possibly restricting the range } \\
\text { required to observe significant differences } \\
\text { between groups. }\end{array}$ \\
\hline $\begin{array}{l}\text { Courneya et } \\
\text { al. (2007a): }\end{array}$ & $\begin{array}{l}\mathrm{N}=242 \text {; patients with } \\
\text { stages } 1 \text { to } 111 \mathrm{~A} \mathrm{BC} \text {, } \\
\text { commencing adjuvant } \\
\text { chemotherapy }\end{array}$ & $\begin{array}{l}\text { Multicentre } \\
\text { RCT (B1) }\end{array}$ & $\begin{array}{l}\text { To evaluate impact of supervised aerobic exercise } \\
\text { training (AET) and resistance exercise (RET) vs usual } \\
\text { care on fatigue (secondary endpoint). } \\
\text { Instrument(s): Functional Assessment of Cancer } \\
\text { Therapy-Anemia scale (FACT-An). }\end{array}$ & $\begin{array}{l}\text { Neither AET or RET significantly improved } \\
\text { fatigue, yet positive trends noted for the } \\
\text { exercise groups. } \\
\text { Limitations: } 70 \% \text { adherence, } 33 \% \\
\text { recruitment rate and ethnically } \\
\text { homogenous sample. }\end{array}$ \\
\hline $\begin{array}{l}\text { Courneya et } \\
\text { al. (2007b): }\end{array}$ & $\begin{array}{l}\mathrm{N}=242 \text {; patients with } \\
\text { stages } 1 \text { to } 111 \mathrm{~A} \mathrm{BC} \\
\text { commencing adjuvant } \\
\text { chemotherapy. } \\
\text { Six-month follow up } \\
\text { data obtained from } 201 \\
\text { participants }\end{array}$ & $\begin{array}{l}\text { Multicentre } \\
\text { RCT (B1) }\end{array}$ & $\begin{array}{l}\text { Six-month post-intervention follow-up of ( } 2007 a) \\
\text { study evaluating impact of aerobic exercise training } \\
\text { (AET) and resistance exercise intervention (RET) on } \\
\text { fatigue (secondary endpoint). } \\
\text { Instrument(s): FACT-An }\end{array}$ & $\begin{array}{l}\text { Participants who indicated adherence to } \\
\text { both } A E T \text { and RET during follow-up period } \\
\text { reported improved levels of fatigue } \\
\text { ( } p=.013) \text {. } \\
\text { Limitations: reliance on self-reporting, } \\
\text { differential loss to follow-up amongst } \\
\text { groups and failure to acquire follow up } \\
\text { data of objective end points. }\end{array}$ \\
\hline $\begin{array}{l}\text { Courneya et } \\
\text { al. (2009): }\end{array}$ & $\begin{array}{l}\mathrm{N}=122 ; \text { patients with } \\
\mathrm{HL} \text { or } \mathrm{NHL} \text { receiving } \\
\text { chemotherapy or no } \\
\text { treatments }\end{array}$ & $\begin{array}{l}\text { Single centre } \\
\mathrm{RCT}(\mathrm{B} 1)\end{array}$ & $\begin{array}{l}\text { To evaluate impact of } 12 \text { weeks of supervised AET vs } \\
\text { usual care (UC) on physical functioning and on } \\
\text { fatigue (secondary endpoint). } \\
\text { Instrument(s): FACT-An fatigue subscale }\end{array}$ & $\begin{array}{l}\text { At post-intervention, fatigue levels in the } \\
\text { AET group were better than in UC group } \\
(p=.013) \text {. } \\
\text { Limitations: sample heterogeneity, limited } \\
\text { power to determine subgroup effects, } \\
\text { short duration of intervention, } 25 \% \\
\text { recruitment rate. }\end{array}$ \\
\hline
\end{tabular}




\begin{tabular}{|c|c|c|c|c|}
\hline $\begin{array}{l}\text { Goldstein et } \\
\text { al. (2012): }\end{array}$ & $\begin{array}{l}\mathrm{N}=218 \text {; patients with } \\
\text { stage } 1 \text { or } 11 \mathrm{BC} \text { post- } \\
\text { surgery commencing } \\
\text { adjuvant treatment } \\
\text { (chemotherapy, } \\
\text { radiotherapy, chemo- } \\
\text { radiotherapy or } \\
\text { endocrine therapy). }\end{array}$ & $\begin{array}{l}\text { Five year } \\
\text { prospective } \\
\text { cohort study } \\
\text { (B3) }\end{array}$ & $\begin{array}{l}\text { To examine the early natural history of cancer } \\
\text { related fatigue (CRF) including incidence and } \\
\text { predictors. } \\
\text { Instrument(s): Somatic and Psychological Health } \\
\text { Report (SPHERE) }\end{array}$ & $\begin{array}{l}\text { Case rate for fatigue was } 24 \% \text { after surgery } \\
\text { and } 31 \% \text { at end of treatment, although it } \\
\text { was persistent for some at } 6 \text { months (11\%) } \\
\text { and } 12 \text { months ( } 6 \% \text { ). Persistent CRF } \\
\text { predicted by tumour size. CRF associated } \\
\text { with significant disability and healthcare } \\
\text { utilization. } \\
\text { Limitations: not all patients participated in } \\
\text { the main cohort and estimate of incidence } \\
\text { at } 5 \text { years was cross-sectional and did not } \\
\text { assess potential confounding clinical } \\
\text { factors such as cancer recurrence. }\end{array}$ \\
\hline $\begin{array}{l}\text { Ligibel et al. } \\
\text { (2010): }\end{array}$ & $\begin{array}{l}\mathrm{N}=41 ; \text { patients with } \\
\text { stage } 1-111 \mathrm{BC} \\
\text { receiving adjuvant or } \\
\text { neoadjuvant } \\
\text { chemotherapy and/or } \\
\text { radiation therapy. }\end{array}$ & $\begin{array}{l}\text { Single-arm } \\
\text { pilot study } \\
\text { (B3) }\end{array}$ & $\begin{array}{l}\text { To evaluate changes in exercise behaviours. } \\
\text { Secondary aim: assessment of changes in fatigue } \\
\text { following a home-based, } 12 \text {-week moderate- } \\
\text { intensity aerobic exercise intervention. Exercise } \\
\text { counselling via telephone. } \\
\text { Instrument(s): EORTC QLQ C-30. }\end{array}$ & $\begin{array}{l}\text { Trend towards improvements in fatigue } \\
(p=.08) . \\
\text { Limitations: small single arm pilot study. } \\
\text { Differences in chemotherapy and } \\
\text { radiotherapy completion time-frame } \\
\text { limiting ability to confidently assert that } \\
\text { decreases in fatigue were due to exercise } \\
\text { intervention rather than treatment } \\
\text { completion. }\end{array}$ \\
\hline $\begin{array}{l}\text { Munir et al., } \\
\text { (2011): }\end{array}$ & $\begin{array}{l}\mathrm{N}=31 \text {; patients with } \\
\text { stage } 1-111 \mathrm{BC} \\
\text { commencing adjuvant } \\
\text { chemotherapy }\end{array}$ & $\begin{array}{l}\text { Mixed } \\
\text { methods } \\
\text { study (B3) }\end{array}$ & $\begin{array}{l}\text { To explore what healthcare information and } \\
\text { supports are available to assist patients to } \\
\text { understand the effects of chemotherapy on daily } \\
\text { functioning at home and work. } \\
\text { Primarily focused on cognitive problems. } \\
\text { Semi-structured interviews explored changes in and } \\
\text { impact of fatigue. } \\
\text { Instrument(s): Fatigue Severity Scale } \\
\text { Intervention validation questionnaire }\end{array}$ & $\begin{array}{l}\text { Self-reported fatigue experienced by } \\
\text { majority and increased across the study } \\
\text { period ( } \mathrm{p} \leq .001) \text {. Subjective cognitive } \\
\text { functioning positively correlated with } \\
\text { fatigue (<.05). All received information } \\
\text { regarding effects of treatment related } \\
\text { fatigue. } \\
\text { Limitations: small exploratory study based } \\
\text { at one clinical site. Did not control for type } \\
\text { of chemotherapy or surgery variables. } \\
\text { Potential participant self-selection. }\end{array}$ \\
\hline $\begin{array}{l}\text { Spichiger et } \\
\text { al. (2012): }\end{array}$ & $\begin{array}{l}\mathrm{N}=19 \text {; patients } \\
\text { receiving }\end{array}$ & $\begin{array}{l}\text { Qualitative } \\
\text { study (B3) }\end{array}$ & $\begin{array}{l}\text { To explore patients perspectives of fatigue, with } \\
\text { particular focus on communication with healthcare }\end{array}$ & $\begin{array}{l}\text { Reported receiving minimal fatigue } \\
\text { management support after initial }\end{array}$ \\
\hline
\end{tabular}


chemotherapy for any

stage of breast,

colorectal, or lung

cancer or lymphoma

employing

'aspects' of

Grounded

Theory professionals (HCPs), self-care activities and the perceived effectiveness of both.

Interviews conducted with patients after third chemotherapy cycle.
Wanchai et

al. (2011):
28 eligible studies focusing on $\mathrm{BC}(\mathrm{BC})$ during treatment $(\mathrm{n}=19,68 \%)$, and $B C$ survivors posttreatment $(n=9,32 \%)$

\section{Systematic} review (A2)

(75\% RCTs, $25 \%$ quasiexperimental)
To critically review literature on nonpharmacological supportive strategies for patients experiencing CRF. Search conducted on MEDLINE and CINAHL databases.

Included papers published in English from 20002010.

Instrument(s): Both unidimensional and multidimensional assessment tools used in reviewed studies.

To examine daily fatigue patterns during third cycle of chemotherapy and determine if fatigue trajectories differ based on exercise or chemotherapy modality. Original study tested the effectiveness of a systematic exercise intervention on fatigue Instrument(s): Daily fatigue diary incorporating a numeric rating scale; Surgeon General's Guideline for Physical Activity (US DHHSa, 1996) information provided by HCPs. Various intuitive self-care approaches employed including rest but difficulty explaining rationale for or effectiveness of chosen measures.

Adequate and systematic information provision needed along with continuous assessment.

Limitations: recruitment in one hospital, small sample size; data saturation (although not sought) was not achieved. Exercise (both home based and supervised) and other strategies promoting exercise may positively impact on CRF. Other strategies likely to be effective include education and counselling, sleep therapy (incorporating, stimulus control, sleep restriction and sleep hygiene) and complementary therapies (CT) such as polarity therapy (energy healing), tai chi and restorative yoga although further research is needed for CT.

Limitations related to methodological weaknesses in some of the studies reviewed.

Patterns of change in fatigue levels did not differ between exercisers and nonexercisers, yet non-exercisers reported higher fatigue levels throughout the third cycle of chemotherapy.

Limitations: homogenous sample, absence of baseline measurement for comparison and acknowledgment that daily diary may not fully reflect symptom experience. 


$\begin{array}{lll}\text { Peterson et } & \mathrm{N}=99 ; \text { patients with } & \text { Multicentre } \\ \text { al. (2009): } & \text { stage 1-1V colorectal } & \text { RCT (B1) } \\ & \text { cancer who } & \\ & \text { experienced oral } & \\ & \text { mucositis (OM) (WHO } \\ & \text { zgrade 2) while } \\ & \text { receiving the first cycle } \\ & \text { of chemotherapy } \\ & \text { (primary treatment } \\ & \text { modality) }\end{array}$

Lee et al. $\quad \mathrm{N}=112$; patients with (2008)

Dibble et al. $\quad \mathrm{N}=303$; Patients (2004)

receiving chemotherapy for BC

Secondary data analysis of a

longitudinal, multicentre, RCT (tested the effectiveness of a systematic exercise intervention for CRF and associated symptoms nausea) (B3)

Multicentre longitudinal descriptive

\section{Oral mucositis (OM)}

To evaluate the safety and efficacy of high dose and High dose rhITF and low dose rhITF

low dose recombinant human intestinal trefoil factor significantly reduced the incidence and (rhITF) vs placebo as a topical oral spray for the prevention and treatment of OM.

Instrument(s): WHO OM Grading Scale and Oral Mucositis Assessment Scale (OMAS)

\section{Nausea} including study (B3) severity of OM. Particular benefit was observed 7-14 days after commencement of chemotherapy.

Limitations: small sample size which likely resulted in the low frequency of grade 3-4 mucositis, therefore; the impact of rhITF in this higher-risk group can only be inferred.

To determine the relationship between nausea intensity and a moderate level of aerobic exercise during and after adjuvant cancer treatment.

Instrument(s): Nausea intensity (0-10 numeric scale), exercise status and Karnofsky Performance Scale (KPS) were measured through patient self-report. Data collected at three time-points.

\section{Vomiting}

To describe the incidence and intensity of chemotherapy induced vomiting (CIV) for BC since the advent of $5-\mathrm{HT}_{3}$ antagonists. Instrument(s): Daily log consisting of the three-item
Although generally low for all participants, nausea intensity was lower for exercisers than for non-exercisers ( $p=.03$ ) at T2 (end of adjuvant chemotherapy) while baseline (T1) and end of study (T3) nausea intensity scores did not differ significantly between the groups.

Limitations: unidimensional measurements of nausea, infrequent exercise status measurements, non-measurement of nausea intensity during chemotherapy and inability to determine if $\mathrm{T} 1$ nausea was anticipatory or delayed.

Despite the use of $5-\mathrm{HT}_{3}$ antagonists, both acute and delayed CIV continue to be a problem for some BC patients (younger age, higher BMI, minority women). 
vomiting experience

subscale from Rhodes Index of Nausea, Vomiting and Retching (INVR)

Demographic and clinical questionnaires

\section{Nausea and Vomiting}

\section{Fernandez- $\quad \mathrm{N}=160$; patients \\ Open}

Ortega et al. receiving moderate to

(2012): highly emetogenic chemotherapy for various types of cancer including breast $(44 \%)$ and colorectal (6.2\%)

cancers

$\begin{array}{lll}\begin{array}{l}\text { Tatham et al. } \\ \text { (2013): }\end{array} & \text { studies (4 RCTs, } 2 & \text { Systematic } \\ \text { Case Series) } & & \text { review (A2) }\end{array}$ multicentre

observational

study (B3)
To analyse the impact of chemotherapy induced nausea and vomiting (CINV) associated with moderate/highly emetogenic chemotherapy on patients QoL.

Instrument(s) Patient diary, Visual Analog Scale (VAS) (nausea), functional living index-emesis (FLIE)

\section{Pain}

To determine whether exercise therapy is more effective than no therapy in reducing shoulder pain for women undergoing treatment of $\mathrm{BC}$, as well as to identify which exercise type is most effective and appropriate outcome measures to assess shoulder pain. Searches undertaken in PEDro, CINAHL, PubMed, Ovid MEDLINE and AMED, for relevant publications up to and including April 2011.
Although likely to be beneficial for those experiencing more CIV, few medication changes (8\%) were made between cycles. Limitations: study sites may have been those where vomiting was a particular problem, participants only followed over two cycles of chemotherapy. Note: study undertaken prior to use of neurokinin 1 receptor antagonists.

Patients receiving high or moderate CINV regimens experienced significant nausea (31\%) and vomiting (45\%) despite administration of optimal antiemetic prophylaxis and both symptoms negatively impacted on their QoL.

Limitations: real incidence of nausea may be less as self-administered questionnaire may have overestimated this symptom. Note: study undertaken prior to use of neurokinin 1 receptor antagonists.

Exercise may be beneficial in reducing shoulder pain related to $B C$ treatment but more high quality studies are warranted. Valid outcome measures such as the Brief Pain Inventory (BPI) and the visual analogue scale (VAS) appear effective in evaluating patients with shoulder pain and monitoring the initial and long-term effects of treatment plans.

Limitations: low number of relevant studies and low methodological quality of studies. 


$\begin{array}{lll}\text { Amara } & 3 \text { studies identified } & \text { Literature } \\ \text { (2008): } & \text { (Clinical trials) } & \text { review (A2) }\end{array}$

(2008): $\quad$ (Clinical trials) review (A2)

Speck et al.

(2012):

Wang et al. (2007):
$\mathrm{N}=25$; patients with $\mathrm{BC}$ who had received at least two cycles of taxane-based chemotherapy. Either currently or within 6 months of treatment (neoadjuvant, adjuvant, metastatic) (stratified to ensure half with and without documented CIPN)

$\mathrm{N}=86$; patients with metastatic colorectal cancer (MCRC)

receiving chemotherapy
Descriptive qualitative study (B3)

RCT (pilot study) (B1)

\section{Peripheral Neuropathy (CIPN)}

To evaluate the role of glutamine in the reduction of Two studies reported that oral glutamine chemotherapy induced peripheral neuropathy (CIPN). PubMed searched for primary studies (1990 - May 2008).

To assess the efficacy of oral glutamine (15g twice a day for seven days every two weeks) for preventing CIPN in patients receiving oxaliplatin for MCRC. Instrument(s): National Cancer Institute Common Toxicity Criteria ( $\mathrm{NCl}-\mathrm{CTC}$ ) and various neurological assessments

\section{Multiple Symptoms}

To explore the cancer symptom experience, self-care was effective in decreasing CIPN associated with high dose paclitaxel while another study found it effective for CIPN in patients with colorectal cancer being treated with oxaliplatin. However, larger, well designed placebo controlled RCTs need to be conducted.

Limitations: Non SR conducted through PubMed only; also, methodological limitations of the studies reviewed. Various self-management strategies employed to manage symptoms of CIPN including exercise, mindfulness, occupational therapy, and environmental planning.

Limitations: potential for misclassification, information bias and issue of generalisability.

A significantly lower incidence of both grade 1-2 CIPN after chemotherapy cycle 2 $(p=.04)$ and grade $3-4$ CIPN after cycles 4 $(p=.05)$ and $6(p=.04)$ in the glutamine group.

Limitations: non-placebo controlled, unblinded and relatively small sample size. 


\begin{tabular}{|c|c|c|c|c|}
\hline (2007): & $\begin{array}{l}\text { receiving a second or } \\
\text { third cycle of } \\
\text { chemotherapy for } \\
\text { cancers of the lung } \\
(24 \%) \text {, nasopharynx } \\
(24 \%) \text {, gastrointestinal } \\
\text { tract }(20 \%) \text {, } \\
\text { ovary/uterus (16\%), } \\
\text { breast }(12 \%), \text { or other } \\
\text { cancer type }(4 \%) .\end{array}$ & $\begin{array}{l}\text { exploratory } \\
\text { cohort Study } \\
\text { (B3) }\end{array}$ & $\begin{array}{l}\text { strategies, and quality of life (QoL) among first } \\
\text { generation Chinese Americans. Instrument(s): Suinn- } \\
\text { Lew Acculturation Scale, Memorial Symptom } \\
\text { Assessment Scale (MSAS), Self-Care Diary, } \\
\text { Multidimensional QoL Scale-Cancer and Short-Form } \\
36 \text { Health Survey. }\end{array}$ & $\begin{array}{l}\text { experiencing } 14 \text { symptoms weekly and } \\
\text { used approximately two self-care } \\
\text { strategies per symptom. Strategies used } \\
\text { were considered to be low to moderate in } \\
\text { effectiveness. Approximately } 20 \% \text { used } \\
\text { Traditional Chinese Medicine. } \\
\text { Limitations: small sample size in one } \\
\text { setting and no qualitative data on } \\
\text { symptom experience. }\end{array}$ \\
\hline $\begin{array}{l}\text { Courneya et } \\
\text { al. (2013): }\end{array}$ & $\begin{array}{l}\mathrm{N}=301 \text {; patients with } \\
\text { stages } 111 \mathrm{C} \mathrm{BC} \\
\text { commencing adjuvant } \\
\text { chemotherapy }\end{array}$ & $\begin{array}{l}\text { Multicentre } \\
\text { RCT (B1) }\end{array}$ & $\begin{array}{l}\text { To compare two different doses and types of } \\
\text { exercise for improving physical functioning/ } \\
\text { symptom management. Standard dose: } 25-30 \\
\text { minutes of aerobic exercise (STAN) compared to a } \\
\text { higher dose of supervised exercise (HIGH) (50- } 60 \\
\text { minutes) and a combined dose of } 50 \text { to } 60 \text { minutes } \\
\text { of aerobic and resistance exercise (COMB). } \\
\text { Instrument(s): relevant subscales of Medical } \\
\text { Outcomes Survey Short Form (SF-36) and Functional } \\
\text { Assessment of Cancer Therapy (FACT) }\end{array}$ & $\begin{array}{l}\text { Although not superior to standard doses } \\
\text { on SF- } 36 \text { physical functioning scale, a } \\
\text { higher volume of aerobic or combined } \\
\text { exercise are feasible and safe during BC } \\
\text { chemotherapy and may be superior to } \\
\text { standard volumes for managing } \\
\text { deterioration in physical functioning and } \\
\text { certain symptoms such as bodily pain, } \\
\text { fatigue and endocrine symptoms. } \\
\text { Limitations: } 41 \% \text { recruitment rate, } \\
\text { demographically homogenous sample, } \\
\text { selection biases and adherence differences } \\
\text { across groups. }\end{array}$ \\
\hline $\begin{array}{l}\text { Kirshbaum } \\
\text { (2006): }\end{array}$ & $\begin{array}{l}29 \text { articles focusing } \\
\text { predominantly on } B C \\
\text { (BC) }\end{array}$ & $\begin{array}{l}\text { Systematic } \\
\text { review }(A 2)\end{array}$ & $\begin{array}{l}\text { To critically review the literature on the benefits of } \\
\text { whole body exercise for various outcomes (including } \\
\text { fatigue) during and after BC treatment. Searches } \\
\text { undertaken in Medline, EMBASE, CINAHL, British } \\
\text { Nursing Index and the Cochrane Library as well as } \\
\text { hand searches of Medicine and Science in Sports and } \\
\text { Exercise journal and various cancer journals. } \\
\text { Included papers published in English from 1985- } \\
2004 \text {. }\end{array}$ & $\begin{array}{l}\text { The evidence supporting the benefit of } \\
\text { exercise for CRF was particularly strong. } \\
\text { Additional studies of higher } \\
\text { methodological quality are warranted. } \\
\text { Limitations: methodological limitations of } \\
\text { the studies reviewed. }\end{array}$ \\
\hline $\begin{array}{l}\text { Maguire et al. } \\
\text { (2009): }\end{array}$ & $\begin{array}{l}\mathrm{N}=24 \text {; patients } \\
\text { receiving adjuvant }\end{array}$ & $\begin{array}{l}\text { Prospective, } \\
\text { observational }\end{array}$ & $\begin{array}{l}\text { To develop and test a side effect risk modelling tool } \\
\text { (ASyMSC-SERAT) to predict chemotherapy induced }\end{array}$ & $\begin{array}{l}\text { Nausea, vomiting, fatigue and hand foot } \\
\text { syndrome were predicted with a high level }\end{array}$ \\
\hline
\end{tabular}




\section{chemotherapy for BC study (B2)}

Loprinzi et al. Review focused on (2008):

premenopausal women with $\mathrm{BC}$.

Literature review (A2)

symptoms (nausea, vomiting, mucositis, hand foot syndrome, diarrhoea, fatigue) and to identify additional data to incorporate into the tool. Instrument(s): Questionnaire (integration of the Common Toxicity Criteria Adverse Events (CTCAE) grading system and the Chemotherapy Symptom Assessment Scale (C-SAS).

To review literature regarding symptom management in pre-menopausal women with $\mathrm{BC}$ (including CRF and CIPN).

Searches undertaken in MEDLINE, Current Contents, PubMed. Also, included were references from relevant articles and abstracts and reports from meetings. Included papers published in English from 19802006.

Exploratory study (B3)
Nakaguchi et al. (2013):
$\mathrm{N}=439$; patients with different cancers at various stages (most advanced) including breast (36\%) and colorectal (24.4\%) cancer and lymphomas (4.6\%). $\mathrm{N}=17$ Oncology
To assess the accuracy of oncology nurses recognition of supportive care needs and symptoms of their patients undergoing chemotherapy. Instrument(s): Patients self-administered ShortForm Supportive Care Needs Survey (SCNS-SF34), European Organisation for Research and Treatment of Cancer Quality of Life-C30 questionnaire (EORTC QLQ-C30), and Hospital Anxiety and Depression Scale (HADS). of accuracy supporting the future development and application of ASyMS(C)SERAT for predicting chemotherapy induced symptoms.

Limitations: sample size, possible differences in completion of electronic vs paper questionnaire and design of tool for four rather than standard 6-8 cycles of chemotherapy.

CRF: Exercise has been shown to positively impact on CRF. Current recommendations include moderate walking, building up to

$30 \mathrm{~min} /$ day, three or more times per week. Pharmacological and herbal preparations, such as modafinil, long-acting methylphenidate and Wisconsin ginseng, are being studied but not recommended for clinical practice currently.

CIPN: Gabapentin, lamotrigine, and nortriptyline have all been tested in randomized, placebo-controlled, doubleblinded research studies; however, none have demonstrated any clear benefit for CIPN.

Limitations: Non SR.

Although the prevalence of physical symptoms not specific to chemotherapy (constipation, insomnia, dyspnea, pain) were high, they were less likely to be recognized by ON than symptoms associated with chemotherapy, such as fatigue and appetite loss. Overall, nurses' awareness of their patients' supportive care needs, physical and psychological 
nurses (ON), based in

outpatient

chemotherapy units

with a mean of 10

years' experience as a

nurse.

O'Shaughnessy Patients receiving

(2007) adjuvant treatment for BC.
ON were blinded to their patients' questionnaire responses and were asked to complete a nurse questionnaire assessing the same endpoints.

Literature review (A2)

To discuss new guidelines for the supportive treatment of patients undergoing adjuvant treatment for $\mathrm{BC}$ and to evaluate novel strategies that can be used to improve the safety of these highly effective regimens.

Review focused on febrile neutropenia

(FN)/infection and cardiac toxicity.

Smithies et al., $\quad \mathrm{N}=19$; patients with (2009): stages 1 to $111 \mathrm{BC}$ commencing adjuvant chemotherapy.
Exploratory, descriptive study (B3)
To assess the value of, and perceived need for a telephone call to $\mathrm{BC}$ patients on the weekend following the initiation of chemotherapy. Instruments: Telephone questionnaire (incorporating a comprehensive list of possible side effects). Demographic and oncology physician questionnaire to document number and nature of calls from patients. symptoms were less than optimal in routine care.

Limitations: Potential selection bias, different assessment measures for patients and nurses may have influenced results.

Nurse related contextual issues (e.g. workload/rapport) may have impacted on accuracy but were not investigated.

The NCCN and ASCO guidelines for colony stimulating factor (CSF) use now recommend routine CSF factor administration with cycle one for chemotherapy regimens associated with a $\geq 20 \%$ risk of $\mathrm{FN}$ or in high risk patients even if risk associated with regimen is < $20 \%$.

Limitations: Non SR; methodological limitations of the studies reviewed.

All participants clearly indicated that a telephone call shortly after the initiation of treatment can be beneficial with regard to teaching and/or reminding them about whom to contact for help. Conversely, the physicians did not see the need for such an intervention.

Limitations: small sample size, limited generalizability, sample homogeneity and data entry was by same person who conducted the telephone intervention. 


\begin{tabular}{|c|c|c|c|c|}
\hline $\begin{array}{l}\text { Wu et al. } \\
\text { (2008): }\end{array}$ & $\begin{array}{l}\text { Patients receiving } \\
\text { chemotherapy for } \\
\text { colorectal cancer. } \\
\text { Four randomized } \\
\text { studies involving a } \\
\text { total of } 342 \text { patients. }\end{array}$ & $\begin{array}{l}\text { Cochrane } \\
\text { review (A1) }\end{array}$ & $\begin{array}{l}\text { To assess the effect of herbal medicines on } \\
\text { chemotherapy-related side effects, quality of life } \\
\text { and objective measures of immune function. } \\
\text { Searches conducted on Cochrane Library, MEDLINE, } \\
\text { EMBASE, Chinese Biomedical Base and a hand } \\
\text { search of Chinese journals ranging from 1966-2003. }\end{array}$ & $\begin{array}{l}\text { Compared with patients treated with } \\
\text { chemotherapy alone, patients treated with } \\
\text { chemotherapy and Huangqi decoctions } \\
\text { were less likely to experience nausea and } \\
\text { vomiting or low white cell counts and there } \\
\text { was no evidence of harm from their use. } \\
\text { Limitations: available studies were limited } \\
\text { in number, small in size and of low quality. } \\
\text { Authors noted that chemotherapy } \\
\text { regimens used in the studies were not } \\
\text { typical of those used worldwide. }\end{array}$ \\
\hline
\end{tabular}




\section{Appendix 3: Description of grey literature}

Table 3 Participating clinical sites: symptom management protocols

\begin{tabular}{|c|c|c|c|c|c|c|c|c|c|c|c|}
\hline Clinical site & Fatigue & Nausea & Vomiting & $\begin{array}{l}\text { Oral } \\
\text { Mucositis }\end{array}$ & CIPN & Diarrhoea & Constipation & $\begin{array}{l}\text { Febrile } \\
\text { neutropenia } \\
\text { /Infection }\end{array}$ & PPE & Pain & $\begin{array}{l}\text { Response from } \\
\text { co-investigator/ } \\
\text { Clinical site }\end{array}$ \\
\hline Clinical site: a & $\sqrt{ }$ & $\sqrt{ }$ & $\sqrt{ }$ & $\sqrt{ }$ & $\sqrt{ }$ & $\sqrt{ }$ & $\sqrt{ }$ & $\checkmark$ & & $\sqrt{ }$ & \\
\hline Clinical site: $b$ & & $\checkmark$ & $\checkmark$ & $\checkmark$ & & $\checkmark$ & $\begin{array}{l}\text { Self-care } \\
\text { advice only } \\
\text { provided }\end{array}$ & $\checkmark$ & & & \\
\hline Clinical site: c & & $\checkmark$ & $\sqrt{ }$ & $\sqrt{ }$ & & $\sqrt{ }$ & & & $\checkmark$ & & \\
\hline Clinical site: $d$ & & $\checkmark$ & $\checkmark$ & $\checkmark$ & & $\sqrt{ }$ & $\begin{array}{l}\text { Self-care } \\
\text { advice only } \\
\text { provided }\end{array}$ & $\checkmark$ & & & \\
\hline Clinical site: e & & $\checkmark$ & $\sqrt{ }$ & $\sqrt{ }$ & & $\sqrt{ }$ & & $\sqrt{ }$ & & & \\
\hline Clinical site: $f$ & & $\begin{array}{l}\text { Self-care } \\
\text { advice only } \\
\text { provided }\end{array}$ & $\begin{array}{l}\text { Self-care } \\
\text { advice only } \\
\text { provided }\end{array}$ & $\begin{array}{l}\text { Self-care } \\
\text { advice only } \\
\text { provided }\end{array}$ & & $\begin{array}{l}\text { Self-care } \\
\text { advice only } \\
\text { provided }\end{array}$ & $\begin{array}{l}\text { Self-care } \\
\text { advice only } \\
\text { provided }\end{array}$ & $\sqrt{ }$ & & & \\
\hline $\begin{array}{l}\text { Clinical sites: } \\
\mathrm{g} \text { and } \mathrm{h}\end{array}$ & & & & & & & & & & & $\begin{array}{l}\text { Protocols are } \\
\text { based on } \\
\text { international } \\
\text { guidelines }\end{array}$ \\
\hline $\begin{array}{l}\text { Clinical sites: } \\
\text { i-m }\end{array}$ & & & & & & & & & & & $\begin{array}{l}\text { Protocols are } \\
\text { based on } \\
\text { international } \\
\text { guidelines (not } \\
\text { available in } \\
\text { English) }\end{array}$ \\
\hline
\end{tabular}

Symptom management protocol was provided by this clinical site $\sqrt{ }$

Note: it is likely that some of the symptom protocols did not list all of the medications that may have been used subsequently, in particular where guidelines were developed for the purpose of telephone triage. 
Table 4 Fatigue (grey literature)

\begin{tabular}{|c|c|c|c|c|}
\hline \multicolumn{5}{|c|}{ Fatigue (symptom management and self-care advice) } \\
\hline \multicolumn{5}{|c|}{$\begin{array}{r}\text { International Cancer Organisations clinical practice guidelines/evidencec } \\
\text { (2: American Society for Clinical Oncology (ASCO); 3: National Comprehensive Cancer Network (N } \\
6: \text { United Kingdom Oncology Nursing Society (UK ONS)) } \\
\text { And local clinical site protocols (grey literature) } \\
\text { (Clinical sites: a, b, c, d, e, f) }\end{array}$} \\
\hline Assessment & \multicolumn{4}{|c|}{$\begin{array}{l}\text { Screen every patient at initial visit and at regular intervals (inpatients daily, outpatients at follow up visits }(2,3) \\
\text { Assessment should be systematic using quantitative/semi quantitative measures }(2,3) \text { and patient self-reports }(2,3,5, a) \\
\text { Focused history identifying disease status, treatment }(2,3,6, a) \text {, medications }(2,3,6) \text { including non-prescribed/supplements }(3 \text {, } \\
5) \text {, social support }(3) \text { Review of systems }(3, \text { a) } \\
\text { In-depth fatigue history }(2,3,6) \text { to identify onset, patterns, related factors and impact }(3,6, a) \\
\text { Assess treatable contributing factors (e.g. anaemia, emotional distress, pain, sleep problems, nutritional deficits, comorbidities, } \\
(2,3,5,6, a)\end{array}$} \\
\hline \multirow[t]{3}{*}{ Grade* } & Grade 1 & Grade 2 & Grade 3 & Grade 4 \\
\hline & $\begin{array}{l}\text { Fatigue relieved by } \\
\text { rest }\end{array}$ & $\begin{array}{l}\text { Fatigue not relieved by rest; limiting } \\
\text { instrumental activities of daily living (ADLs) }\end{array}$ & $\begin{array}{l}\text { Fatigue not relieved by rest, limiting self- } \\
\text { care } A D L\end{array}$ & ----------------- \\
\hline & & 12 & 2 L & 1 \\
\hline $\begin{array}{l}\text { Symptom } \\
\text { Management }\end{array}$ & \multicolumn{4}{|c|}{$\begin{array}{l}\text { Patient and family education and counselling regarding known patterns of fatigue associated with treatment }(2,3,5, a) \\
\text { Manage associated symptoms and treatable contributing factors }(2,3,5,6, a) \\
\text { Medication as appropriate for pain, emotional distress, nutritional deficits, sleep disorder }(3,5) \\
\text { Exercise (aerobic and resistance) }(2,3,5, a \text {, d, e), self-monitoring of fatigue }(3, \text { a), energy conservation measures including rest } \\
(3,5,6 \text {, a) } \\
\text { Distraction techniques }(3,5, a) \text {, finding meaning in current situation }(3) \text {, consider referral to rehabilitation specialists }(3, \text { b, e) } \\
\text { Physically based therapies (massage) }(3,5) \text {, relaxation }(3,5) \text {, yoga }(2) \\
\text { Cognitive behavioural therapy (CBT)/behavioural therapy }(2,3,5) \\
\text { Psychoeducational therapies/educational therapies }(2,3,5) \text {, supportive expressive therapies }(3) \\
\text { Nutrition advice/nutritional consultation }(2,5,6, a) \text {, consider psychostimulants after ruling out other causes of fatigue }(2,3,5)\end{array}$} \\
\hline
\end{tabular}


Table 5 Chemotherapy induced nausea and vomiting (grey literature)

Chemotherapy induced nausea and vomiting (CINV) (symptom management and self-care advice)

International Cancer Organisations clinical practice guidelines/evidenced based resources

(1: European Society for Medical Oncology (ESMO); 2: American Society for Clinical Oncology (ASCO); 3: National Comprehensive Cancer Network (NCCN); 4: Multinational Association for Supportive Care in Cancer (MASCC); 5: Oncology Nursing Society (ONS);

6: United Kingdom Oncology Nursing Society (UK ONS))

And local clinical site protocols (grey literature)

(Clinical sites: $a, b, c, d, e, f)$

\begin{tabular}{|c|c|c|c|c|}
\hline Assessment & \multicolumn{4}{|c|}{$\begin{array}{l}\text { Assessment should be ongoing throughout treatment }(2,3) \\
\text { Nausea and/or vomiting history }(6, a, c) \text { and associated symptoms }(6, a) \\
\text { Cancer diagnosis }(6, c) \text {, treatment to date }(6, a) \text {, Medication history }(6, a, c) \text { including antiemetics taken ( } a, c) \\
\text { Assess presence of risk factors for CINV }(1,2,3,4,5, a, b, c, d, e) \\
\text { Identify other potential causes }(3,5,6, b, d, e) \\
\text { Assess for signs of dehydration }(6, a, b, d, e) \text { and establish dietary history (fluid/solid food intake) }(6, a, b, c, d, e) \\
\text { Determine grade of nausea and/or vomiting }(6, a, b, c, d, e)\end{array}$} \\
\hline Grade* & Grade 1 & Grade 2 & Grade 3 & Grade 4 \\
\hline Nausea & $\begin{array}{l}\text { Loss of appetite without } \\
\text { alteration in eating habits }\end{array}$ & $\begin{array}{l}\text { Oral intake decreased without significant } \\
\text { weight loss, dehydration or malnutrition }\end{array}$ & $\begin{array}{l}\text { Inadequate oral caloric or } \\
\text { fluid intake; tube feeding, } \\
\text { TPN, or hospitalization } \\
\text { indicated }\end{array}$ & --.-- \\
\hline \multirow[t]{2}{*}{ Vomiting } & $\begin{array}{l}1-2 \text { episodes (separated by } 5 \\
\text { minutes) in } 24 \mathrm{hrs}\end{array}$ & $\begin{array}{l}3-5 \text { episodes (separated by } 5 \text { minutes) in } \\
24 \mathrm{hrs}\end{array}$ & $\begin{array}{l}\geq 6 \text { episodes (separated by } \\
5 \text { minutes) in } 24 \text { hrs; tube } \\
\text { feeding, TPN or } \\
\text { hospitalization indicated }\end{array}$ & $\begin{array}{l}\text { Life-threatening } \\
\text { consequences; } \\
\text { urgent intervention } \\
\text { indicated }\end{array}$ \\
\hline & 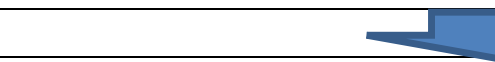 & 5 & 2 & $\square$ \\
\hline $\begin{array}{l}\text { Symptom } \\
\text { Management }\end{array}$ & \multicolumn{2}{|c|}{$\begin{array}{l}\text { Review prescribed antiemetic regimen }(5,6, a, b, d, e, f) \\
\text { Advise to: take small frequent sips of fluids }(6, a, b, d, f) \text {, eat small frequent } \\
\text { amounts of foods }(5,6, a, b, d, f) \text {, avoid spicy, fatty foods }(5, b, d, f) \text {, avoid } \\
\text { strong odours }(5, b, d, f) \text {, try ginger biscuits/foods/fluids }(6, a, b, d, f) \text {, take } \\
\text { antiemetics prior to meals }(5, a) \text { and monitor for signs of dehydration }(6, a) \\
\text { Consider non-pharmacological therapies such as acupuncture/acupressure } \\
(5, b, d, f) \text {, music therapy }(5, a) \text {, relaxation/progressive muscle relaxation }(1 \text {, } \\
4,5, a, b, f) \text {, behavioural therapy with systematic desensitisation for } \\
\text { anticipatory CINV }(1,2,4)\end{array}$} & \multicolumn{2}{|c|}{$\begin{array}{l}\text { Present to hospital for immediate review }(6, a, b \text {, } \\
d, e)\end{array}$} \\
\hline
\end{tabular}




\begin{tabular}{|c|c|}
\hline & $\begin{array}{l}\text { Contact hospital if symptom(s) persists/worsens }(6, a, b) \\
\text { Phone/review within } 12-24 \text { hours (6) }\end{array}$ \\
\hline & 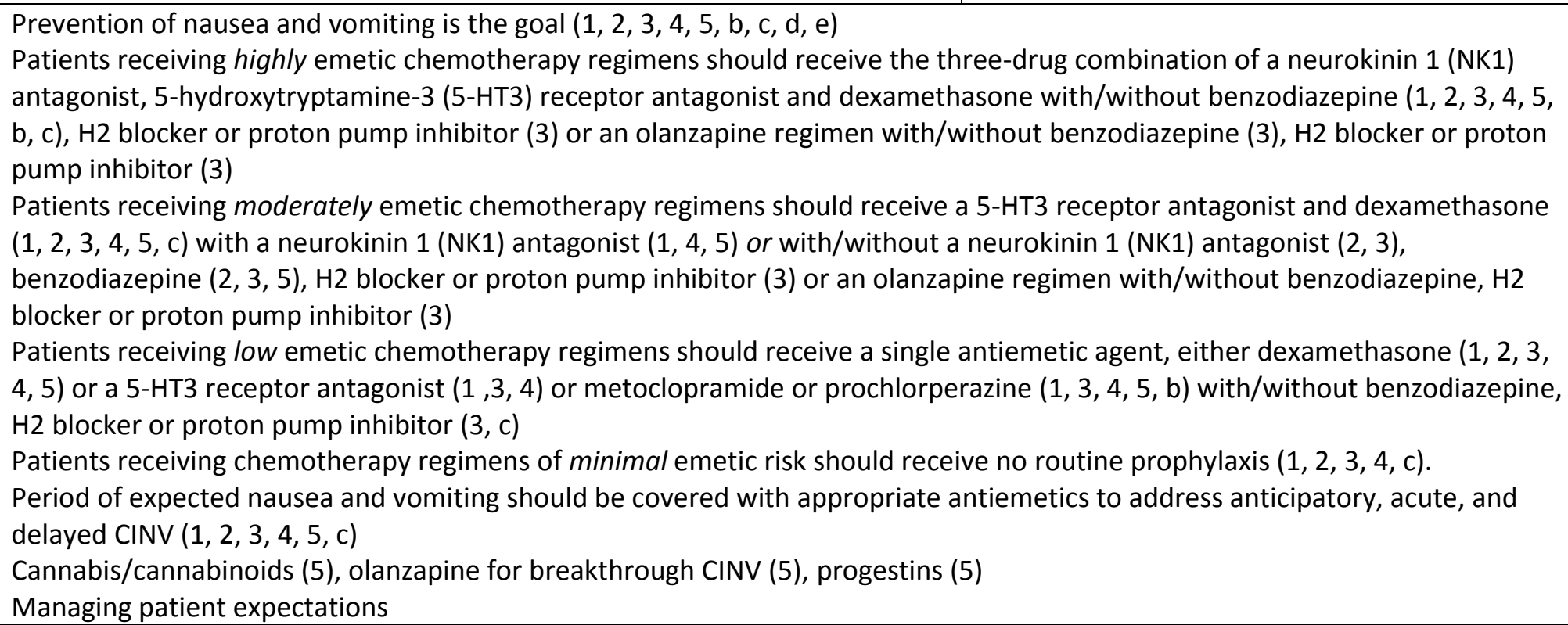 \\
\hline
\end{tabular}


Table 6 Oral Mucositis (grey literature)

\begin{tabular}{|c|c|c|c|c|}
\hline \multicolumn{5}{|c|}{ Oral Mucositis (OM) (symptom management and self-care advice) } \\
\hline \multicolumn{5}{|c|}{$\begin{array}{l}\text { International Cancer Organisations clinical practice guidelines/evidenced based re } \\
\text { ciety for Medical Oncology (ESMO); 4: Multinational Association for Supportive Care in Cance } \\
\text { ety (ONS); 6: United Kingdom Oncology Nursing Society (UK ONS); 8: International Society of } \\
\text { And local clinical site protocols (grey literature) } \\
\text { (Clinical sites: a, b, c, d,e, f) }\end{array}$} \\
\hline Assessment & \multicolumn{4}{|c|}{$\begin{array}{l}\text { Assess for oral mucositis using a valid and reliable instrument (5)/recognised (NCI CTAE/WHO) grading scale }(1,6, a, b, d, e) \\
\text { Mucositis history: severity of OM (presence/extent of ulceration/candida) }(1,6, a, b, c, d, e) \text {, signs of secondary infection }(6, a \text {, } \\
b, d, e) \text {, dehydration }(6, a, b, d, e) \text {, presence of fever }(6, a, b, d, e) \text {, pain }(1,5,6, a, b, d, e) \text {, Assessment of fluid/solid food intake } \\
(1,6, a, b, d, e) \\
\text { Identification of treatment to date }(1,6, a, b, d, e) \text {, medication history including use of mouthwashes/analgesia }(6, a) \\
\text { Careful oral examination of mucous membranes assessment for erythema, ulceration, signs of secondary infection, dehydration } \\
(6, b, d, e) \text {. Swabs if suspicion of bacterial, fungal, viral infections }(6, b, d, e)\end{array}$} \\
\hline \multirow[t]{3}{*}{ Grade* } & Grade 1 & Grade 2 & \begin{tabular}{|c|} 
Grade 3 \\
\end{tabular} & Grade 4 \\
\hline & $\begin{array}{l}\text { ymptomatic or mild } \\
\text { mptoms; intervention } \\
\text { t indicated }\end{array}$ & $\begin{array}{l}\text { Moderate pain; not } \\
\text { interfering with oral intake; } \\
\text { modified diet indicated }\end{array}$ & $\begin{array}{l}\text { Severe pain; interfering with oral } \\
\text { intake }\end{array}$ & $\begin{array}{l}\text { Life-threatening } \\
\text { consequences; urgent } \\
\text { intervention indicated }\end{array}$ \\
\hline & & 2 & 2 & \\
\hline $\begin{array}{l}\text { Symptom } \\
\text { Management }\end{array}$ & \multicolumn{2}{|c|}{$\begin{array}{l}\text { Use oral care protocols/ensure good oral hygiene }(1,5 \text {, } \\
6, a, b, c, d, e, f) \text {, use soft toothbrush }(1,5, a, b, c, f), \\
\text { Saline/sodium bicarbonate mouthwash } 4-6 \text { times/day }(1 \text {, } \\
5, b, c, f) \text {, avoid alcohol based mouthwashes }(1,5, a, b, c \text {, } \\
\text { d, e, f), remove dentures if irritating }(b, d, e) \text {, } \\
\text { Arrange for antifungal prescription }(6, a) \text { if required } \\
\text { Benzydamine }(b, c, d, e) \text { or sucralfate }(a, b, c, d, e) \text { or } \\
\text { lidocaine based }(a, c) \text { mouthwash if required }\end{array}$} & \multicolumn{2}{|c|}{$\begin{array}{l}\text { Present to hospital for review/admission }(6, a) \text {. As for grade } 1 \text {, also: } \\
\text { Intravenous/parenteral hydration if required }(6, b, d, e) \\
\text { Antifungal treatment as required }(6, b, d) \text {, topical acyclovir for } \\
\text { lips/oral acyclovir }(6, b, d, e) / \text { antiviral treatment }(1) \text { for coexisting } \\
\text { viral infection. Benzydamine }(5,6, b, c, d \text {, e) or sucralfate }(6, b, c, d \text {, } \\
\text { e) or doxepin }(1,8) \text { mouthwash as required for pain. Systemic } \\
\text { opioids }(1,6,8, b, c, d, e) \text { as required. Petroleum jelly, yellow/white } \\
\text { soft paraffin or normal lip salve to moisten lips }(b, c, d, e) \text {. } \\
\text { Consult dietician }(6, b, d, e) \text { if inadequate oral intake. }\end{array}$} \\
\hline Prevention & \multicolumn{4}{|c|}{$\begin{array}{l}\text { Use oral care protocols/ensure good oral hygiene }(1,4,5,6,8, a, b, c, d, e, f) \\
\text { Oral cryotherapy in patients receiving bolus } 5 \text {-fluorouracil chemotherapy }(1,4,5,8) \text {, prophylactic chlorhexidine mouth rinses (5) }\end{array}$} \\
\hline
\end{tabular}


Table 7 Chemotherapy induced peripheral neuropathy (grey literature)

\begin{tabular}{|c|c|c|c|c|}
\hline \multicolumn{5}{|c|}{ CIPN (symptom management and self-care advice) } \\
\hline \multicolumn{5}{|c|}{$\begin{array}{r}\text { International Cancer Organisations clinical practice guidelines/evidenced ba } \\
\text { (2: American Society for Clinical Oncology (ASCO); 5: Oncology Nursing Society (ONS); 7: European } \\
\text { And local clinical site protocols (grey literature) } \\
\text { (Clinical sites: a, b, c, d, e,f) }\end{array}$} \\
\hline Assessment & \multicolumn{4}{|c|}{$\begin{array}{l}\text { Comprehensive baseline assessment identifying co-morbidities }(2,7, \text { a) with neurological impact placing patients at higher risk } \\
(2,7) \\
\text { Treatment to date }(7, \text { a), identifying other neurotoxic treatments received }(7) \\
\text { Determine grade of symptom }(2,7, \text { a) } \\
\text { Identify all medications taken }(7, \text { a) (including non-prescribed), supplements }(7) \\
\text { Neurological assessment }(7) \text {; assess falls risk (7) }\end{array}$} \\
\hline \multirow[t]{3}{*}{ Grade* } & Grade 1 & Grade 2 & Grade 3 & Grade 4 \\
\hline & $\begin{array}{l}\text { tic; clinical or } \\
\text { bservations only; loss } \\
\text { don reflexes or } \\
\text { a }\end{array}$ & & & $\begin{array}{l}\text { Life-threatening } \\
\text { consequences; urgent } \\
\text { intervention indicated }\end{array}$ \\
\hline & & 2 & $2 \longdiv { 2 }$ & 12 \\
\hline $\begin{array}{l}\text { Symptom } \\
\text { Management }\end{array}$ & \multicolumn{4}{|c|}{$\begin{array}{l}\text { Duloxetine }(2,5) \\
\text { Tricyclic antidepressants (e.g., nortriptyline or desipramine) }(2,5) \text {; gabapentin }(2,5) \text { and a topical gel treatment containing } \\
\text { baclofen }(10 \mathrm{mg}) \text {, amitriptyline } \mathrm{HCL}(40 \mathrm{mg}) \text {, and ketamine }(20 \mathrm{mg})(2) \text {. (It is reasonable to consider all three agents in the } \\
\text { context of limited treatment options for CIPN and having discussed with patients the potential harms, benefits and costs }(2) \text {. } \\
\text { Consider dose reduction or stopping treatment }(7) \\
\text { Education and support to preserve patient safety }(7) \text { Consider referral to rehabilitation specialist }(7) \\
\text { Assist patients to identify solutions to deal with changes/problems with ADLs/household duties and changes/problems at work } \\
\text { (7) } \\
\text { Educate on principles of foot care and approaches to reduce risk of ischaemic or thermal injury in extremities; avoid exposure to } \\
\text { cold (7). Educate on strategies to prevent symptoms of autonomic dysfunction (e.g. dangling legs prior to standing / adequate } \\
\text { fluid intake) (7). Advise regarding reporting symptom; reassure that CIPN is an expected side effect of treatment (a, b) } \\
\text { Grade 4: Present to hospital for immediate review (a) }\end{array}$} \\
\hline & \multicolumn{4}{|c|}{ *Grades based on the Common Terminology Criteria for Adverse Events (NCI CTCAE V4.0). } \\
\hline
\end{tabular}




\begin{tabular}{|c|c|c|c|c|}
\hline \multicolumn{5}{|c|}{ Diarrhoea (symptom management and self-care advice) } \\
\hline \multicolumn{5}{|c|}{$\begin{array}{l}\text { International Cancer Organisations clinical practice guidelines/evidenced based resources } \\
\text { (5: Oncology Nursing Society (ONS); 6: United Kingdom Oncology Nursing Society (UK ONS)) } \\
\text { And local clinical site protocols (grey literature) } \\
\text { (Clinical sites: a, b, c, d, e, f) }\end{array}$} \\
\hline Assessment & \multicolumn{4}{|c|}{$\begin{array}{l}\text { Diarrhoea history (duration, severity, characteristics, presence of fever, dizziness, abdominal pain /cramping, weakness }(5,6, a \text {, } \\
b, c, d, e, f) \text {, baseline bowel habits }(5,6) \text {. Determine grade of symptom }(5,6, a, b, d, e) \\
\text { Treatment to date }(6, a, b, c, d, e) \text {, Medication history }(6, a, b, c, d, e) \\
\text { Dietary history (fluid/solid food intake) }(5,6, a, b, c, d, e) \\
\text { Full blood count }(6, b, c, d, e) \text {, urea and electrolytes (U\&E) }(6, b, c, d, e), C \text {-reactive protein ( } 6) \text {, stool sample }(6, b, c, d, e)\end{array}$} \\
\hline \multirow[t]{3}{*}{ Grade* } & Grade 1 & Grade 2 & Grade 3 & Grade 4 \\
\hline & $\begin{array}{l}\text { Increase of }<4 \text { stools per day } \\
\text { over baseline; mild increase } \\
\text { in ostomy output compared } \\
\text { to baseline }\end{array}$ & $\begin{array}{l}\text { Increase of } 4-6 \text { stools per day over } \\
\text { baseline; moderate increase in } \\
\text { ostomy output compared to } \\
\text { baseline; }\end{array}$ & $\begin{array}{l}\text { Increase }>7 \text { stools per day over } \\
\text { baseline; incontinence; IV fluids }>24 \\
\text { hours; hospitalization; severe increase } \\
\text { in ostomy output compared to } \\
\text { baseline; interfering with ADL }\end{array}$ & $\begin{array}{l}\text { Life } \\
\text { threatening } \\
\text { consequences } \\
\text { (e.g. } \\
\text { haemodynamic } \\
\text { collapse) }\end{array}$ \\
\hline & 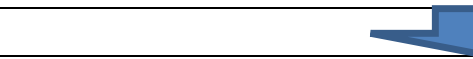 & 2 & 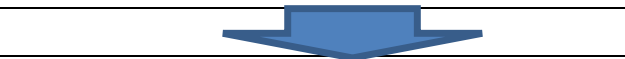 & +12 \\
\hline $\begin{array}{l}\text { Symptom } \\
\text { Management }\end{array}$ & \multicolumn{2}{|c|}{$\begin{array}{l}\text { Review discharge advice, i.e. take loperamide }(5,6, a, b, c, d, e) \text { or } \\
\text { codeine phosphate }(6, a, c, d, e) \text { as prescribed. } \\
\text { Take small frequent meals }(b, c, d, e) \text {, limit intake of certain } \\
\text { food/fluid e.g. caffeine }(6, b, d, e) \text {, fruit juice }(b, e) \text {, alcohol }(6, b, d \text {, } \\
\text { e). Avoid spicy foods (b, d, e), high fibre foods }(6, d, e) \\
\text { If drinking less than } 2-3 \text { litres/day, advise to increase fluid intake }(6 \text {, } \\
\text { a, b, c, d, f) and arrange review within } 12-24 \text { hours }(6, a, b, c, d, e, f) \\
\text { Contact hospital with a view to admission if diarrhoea persists } \\
\text { despite treatment (loperamide as prescribed) and/or new symptoms } \\
\text { such as fever, nausea and vomiting ( } 6, \text { a, b, c, d, e, f) } \\
\text { Stop drugs that may be contributing and consider admission based } \\
\text { on further assessment }(6, a, b, c, d) \text {. Perianal skin care (6) }\end{array}$} & \multicolumn{2}{|c|}{$\begin{array}{l}\text { As for grade } 1-2(6, a, b, d, e) \\
\text { Present to hospital for immediate review }(6, a, b, c, d, e \text {, } \\
\text { f) and management including octreotide }(5,6, c, d, e) \\
\text { IV antibiotics as appropriate }(6, b, c) \\
\text { Codeine phosphate }(b) \text {, budesonide }(b, c, d, e)\end{array}$} \\
\hline & & & & \\
\hline
\end{tabular}


Table 9 Constipation (grey literature)

\begin{tabular}{|c|c|c|c|c|}
\hline \multicolumn{5}{|c|}{ Constipation (symptom management and self-care advice) } \\
\hline \multicolumn{5}{|c|}{$\begin{array}{l}\text { International Cancer Organisations clinical practice guidelines/evidenced based resources } \\
\text { (5: Oncology Nursing Society (ONS); 6: United Kingdom Oncology Nursing Society (UK ONS)) } \\
\text { And local clinical site protocols (grey literature) } \\
\text { (Clinical sites: } a, b, c, d, e, f \text { ) }\end{array}$} \\
\hline Assessment & \multicolumn{4}{|c|}{$\begin{array}{l}\text { Thorough assessment, including normal bowel pattern, medication history }(5,6, a) \text { including use of laxatives }(5, a) \text {, cancer } \\
\text { diagnosis and treatment (a) Physical examination (5) } \\
\text { Determine grade of symptom }(6, a)\end{array}$} \\
\hline \multirow[t]{3}{*}{ Grade* } & Grade 1 & Grade 2 & \begin{tabular}{|c|} 
Grade 3 \\
\end{tabular} & Grade 4 \\
\hline & $\begin{array}{l}\text { Occasional or } \\
\text { intermittent } \\
\text { symptoms; occasional } \\
\text { use of stool softeners, } \\
\text { laxatives, dietary } \\
\text { modification, or } \\
\text { enema }\end{array}$ & $\begin{array}{l}\text { Persistent } \\
\text { symptoms with } \\
\text { regular use of } \\
\text { laxatives or } \\
\text { enemas; limiting } \\
\text { instrumental ADL }\end{array}$ & $\begin{array}{l}\text { Obstipation with manual evacuation indicated; limiting } \\
\text { self-care ADL }\end{array}$ & $\begin{array}{l}\text { Life-threatening } \\
\text { consequences; urgent } \\
\text { intervention indicated }\end{array}$ \\
\hline & 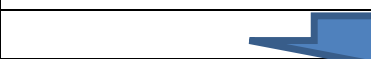 & 1 & 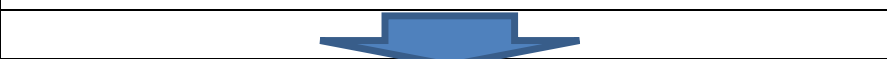 & 原 \\
\hline \multirow[t]{2}{*}{$\begin{array}{l}\text { Symptom } \\
\text { Management }\end{array}$} & \multicolumn{2}{|c|}{$\begin{array}{l}\text { High fibre diet }(5, a, b, d, f) \\
\text { Increase fluid intake }(5,6, a, b, d, f) \text { (eight } \\
8 \text { ounce glasses of fluid } / \text { day) }(5) \\
\text { Exercise }(5, a, b, d, f) \\
\text { Laxatives }(5,6, a)\end{array}$} & $\begin{array}{l}\text { As for Grades } 1 \text { and } 2(5,6, a, b, d, f) \text {. Also: } \\
\text { Review prescribed stool softeners and laxatives, also } \\
\text { other (aggravating) medications }(6, a) \\
\text { Stimulant and/or osmotic laxatives (5) } \\
\text { Consider admission if associated with symptoms of } \\
\text { concern }(6, a)\end{array}$ & $\begin{array}{l}\text { Present to hospital for } \\
\text { immediate review }(6, \text { a) }\end{array}$ \\
\hline & \multicolumn{4}{|c|}{$\begin{array}{l}\text { Prophylactic bowel regimen and opioid rotation for opioid induced constipation (5) } \\
\text { Polyethylene glycol (PEG) (5) stimulant laxatives, stool softeners (5), Methylnaltrexone (5) }\end{array}$} \\
\hline
\end{tabular}


Table 10 Palmar plantar erythrodysesthesia (grey literature)

\section{Palmar plantar erythrodysesthesia (PPE)/Hand-foot syndrome (symptom management and self-care advice)}

International Cancer Organisations clinical practice guidelines/evidenced based resources

(5: Oncology Nursing Society (ONS); 6: United Kingdom Oncology Nursing Society (UK ONS)

And local clinical site protocols (grey literature)

(Clinical sites: a, b, c, d, e, f)

\begin{tabular}{|c|c|c|c|c|}
\hline Assessment & \multicolumn{4}{|c|}{$\begin{array}{l}\text { Identify treatment taken (type and most recent treatment) (6) } \\
\text { Ask about presence of other symptoms (6) } \\
\text { Determine if PPE experienced on previous cycles (6) } \\
\text { Full blood count, urea and electrolytes (6) } \\
\text { Vital signs (6) } \\
\text { Determine grade of symptom (6) }\end{array}$} \\
\hline \multirow{3}{*}{ Grade* } & Grade 1 & Grade 2 & Grade 3 & Grade 4 \\
\hline & $\begin{array}{l}\text { Minimal skin changes or } \\
\text { dermatitis (e.g., erythema, } \\
\text { edema, or hyperkeratosis) } \\
\text { without pain }\end{array}$ & $\begin{array}{l}\text { Skin changes (e.g., } \\
\text { peeling, blisters, } \\
\text { bleeding, oedema) or } \\
\text { pain, not interfering } \\
\text { with function }\end{array}$ & $\begin{array}{l}\text { Severe skin changes (e.g., } \\
\text { peeling, blisters, bleeding, } \\
\text { edema, or hyperkeratosis) } \\
\text { with pain; limiting self-care } \\
\text { ADL }\end{array}$ & ---------------' \\
\hline & r & 5 & +15 & +15 \\
\hline $\begin{array}{l}\text { Symptom } \\
\text { Management }\end{array}$ & $\begin{array}{l}\text { Reassurance (6), emphasise } \\
\text { importance of skin care } \\
\text { regime/regular moisturiser }(6, c) \text {, } \\
\text { advise to contact if symptom } \\
\text { worsens }(6) \text {, consider pyridoxine as } \\
\text { per local policy }(6, c) \text { for patients } \\
\text { on capecitabine, } 5 \mathrm{FU} \text { or liposomal } \\
\text { doxorubicin }\end{array}$ & $\begin{array}{l}\text { Discuss withholding treatment with } \\
\text { medical team until resolved to } \\
\text { grade } 0-1(6) \text {, emphasise } \\
\text { importance of skin care regime }(6 \text {, } \\
\text { c), consider pyridoxine as per local } \\
\text { policy }(6, c)\end{array}$ & \multicolumn{2}{|c|}{$\begin{array}{l}\text { Inform medical team and stop medication until } \\
\text { resolved to grade } 0-1(6)(5) \text { review analgesia and } \\
\text { consider paracetamol if indicated }(6) \text {, emphasise } \\
\text { importance of skin care regime }(6, c) \text {, consider } \\
\text { pyridoxine as per local policy }(6, c)\end{array}$} \\
\hline
\end{tabular}


Table 11 Febrile neutropenia (grey literature)

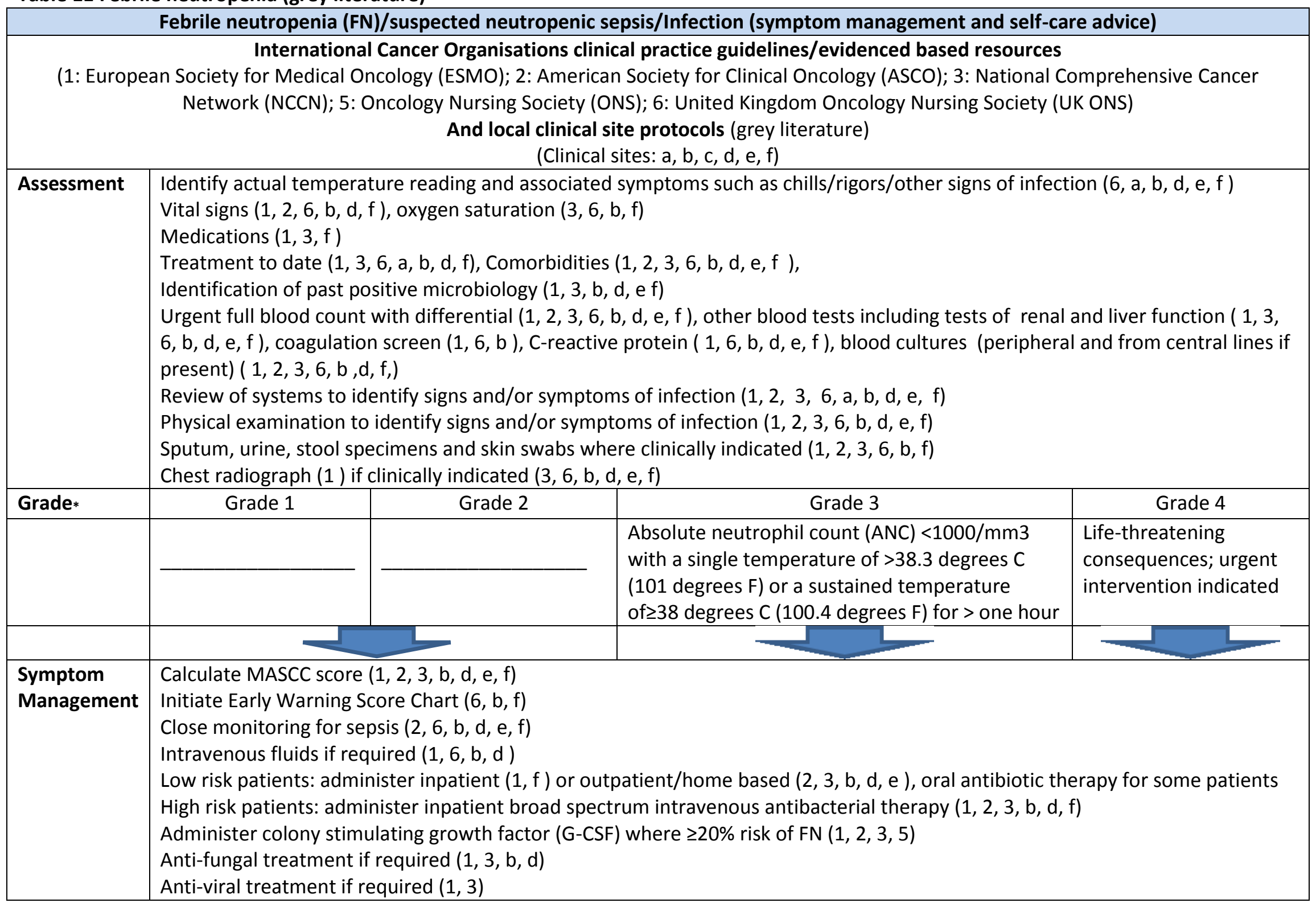




\begin{tabular}{|l|l|}
$\begin{array}{l}\text { Infection } \\
\text { prevention } \\
\text { strategies }\end{array}$ & $\begin{array}{l}\text { Adherence to general infection control recommendations }(3,5) \text {, catheter care bundle for prevention of central line associated } \\
\text { infection }(5) \\
\text { Antibiotic prophylaxis in at risk patients }(3,5) \text {, antifungal prophylaxis in at risk patients }(1,3,5) \text {, Antiviral prophylaxis for select at } \\
\text { risk patients }(3,5) \\
\text { Colony stimulating factors for at risk patients }(1,2,3,5) \\
\text { Hand washing/hand hygiene with alcohol sanitizer }(3,5) \\
\text { Influenza vaccination }(3,5), \text { pneumococcal and meningococcal vaccination }(3,5) \\
\text { Antibiotic abdominal lavage in CRC surgery (5), antimicrobial coated CVC catheters in adults (5), preoperative antibiotics } \\
\text { Chlorhexidine impregnated washcloths, chlorhexidine bath (5) } \\
\text { Environmental interventions (5), pre-construction planning (5) }\end{array}$ \\
\hline \multirow{2}{*}{ *Grades based on the Common Terminology Criteria for Adverse Events (NCI CTCAE V4.0). } \\
\hline
\end{tabular}


Table 12 Pain (grey literature)

\begin{tabular}{|c|c|c|c|}
\hline \multicolumn{4}{|c|}{ Pain (symptom management and self-care advice) } \\
\hline \multicolumn{4}{|c|}{$\begin{array}{l}\text { International Cancer Organisations clinical practice guidelines/evidenced based resources } \\
\text { an Society for Medical Oncology (ESMO); 2: American Society for Clinical Oncology (ASCO); 3: National Comprehensive Cancer } \\
\text { CN); 4: Multinational Association for Supportive Care in Cancer (MASCC); 5: Oncology Nursing Society (ONS); 6: United Kingdom } \\
\text { Oncology Nursing Society (UK ONS); 7: European Oncology Nursing Society (EONS)) } \\
\text { And local clinical site protocols (grey literature) } \\
\text { (Clinical sites: a, b, c, d, e, f) }\end{array}$} \\
\hline Assessment & \multicolumn{3}{|c|}{$\begin{array}{l}\text { Initial and ongoing assessment of pain and of patients with pain at any stage }(1,3) \\
\text { Cancer diagnosis }(3,7, a), \text { cancer treatment }(3,7, a) \text {, pain onset }(1,3,7, a) \text {, location/radiation }(1,3,7, \text { a }) \text {, duration }(1,3,7, a) \text {, } \\
\text { type }(1,3) \text {, character }(1,3,7, a,) \text {, severity (using standardised assessment scale) }(1,3,7 \text {, a ), current analgesia }(1,3, a, 7) \text {, } \\
\text { associated symptoms/aggravating and relieving factors }(1,3,7, a) \text {, comorbidities }(1,3) \text {, interference with } A D L s(1,3) \\
\text { Psychosocial assessment }(1,3,7) \\
\text { Physical examination }(1,3,7) \text {, functional assessment }(1,3) \\
\text { Radiological and/or biochemical investigations }(1,3)\end{array}$} \\
\hline \multirow[t]{3}{*}{ Grade* } & Grade 1 & Grade 2 & Grade 3 \\
\hline & Mild pain & Mild to moderate pain & Moderate to severe pain \\
\hline & +25 & - & +15 \\
\hline \multirow[t]{2}{*}{$\begin{array}{l}\text { Symptom } \\
\text { Management }\end{array}$} & $\begin{array}{l}\text { Nonsteroidal anti- } \\
\text { inflammatory (NSAID) drug ( } 1 \text {, } \\
3,5) \text { and/or } \\
\text { Acetaminophen/paracetamol } \\
(1,5) \text {, consider short acting } \\
\text { opioid (3), consider } \\
\text { adding/adjusting adjuvant } \\
\text { analgesics (3) }\end{array}$ & $\begin{array}{l}\text { Weak opioid such as codeine, tramadol } \\
\text { and dihydrocodeine in combination with } \\
\text { non-opioid analgesics }(1,3) \\
\text { Consider: pain specialty consultation } \\
\text { (3), adding/adjusting adjuvant } \\
\text { analgesics (3) } \\
\text { specific pain syndrome problems (3) }\end{array}$ & $\begin{array}{l}\text { Present to hospital for immediate review (a), } \\
\text { Opioids }(1,5,) \text {, oral morphine (first choice) or } \\
\text { parenterally }(1,3) \\
\text { Consider: pain specialty consultation (3), } \\
\text { adding/adjusting adjuvant analgesics (3) } \\
\text { specific pain syndrome problems (3) }\end{array}$ \\
\hline & \multicolumn{3}{|c|}{$\begin{array}{l}\text { Analgesia for chronic pain should be prescribed on a regular basis rather than on an 'as required' schedule }(1,3) \\
\text { Administer via oral route as a first choice }(1,3,5) \\
\text { Rescue doses of medications in addition to 'around the clock' scheduled doses should be prescribed for breakthrough pain (BTP) } \\
\text { episodes }(1,3) \\
\text { Neuropathic pain should be treated with opioids }+/ \text { - non-opioids }+/ \text { - co-analgesics }(1,3,5) \\
\text { Opioid rotation using an equianalgesic chart if opioid regimen ineffective or if side effects intolerable }(1,3) \\
\text { Laxatives for prophylaxis and management of opioid-induced constipation }(1,3,5)\end{array}$} \\
\hline
\end{tabular}




\begin{tabular}{|l|l|}
\hline & $\begin{array}{l}\text { Anti-emetics for opioid-related nausea and vomiting }(1,3,5) \\
\text { Consider integrative interventions/non pharmacological interventions in conjunction with pharmacological interventions }(b, 5, \\
3,7)\end{array}$ \\
\hline Psychosocial support $(1,3,7)$ and patient and family caregiver education $(1,3,7)$
\end{tabular}

